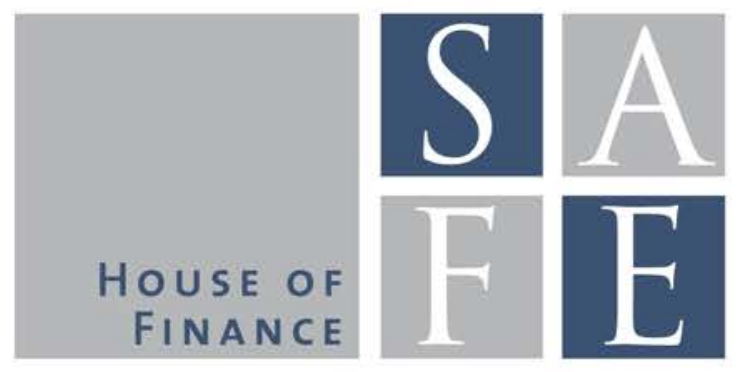

WORKING PAPER SERIES

Patrick Grüning

\title{
International Endogenous Growth, Macro Anomalies, and Asset Prices
}

SAFE Working Paper No. 83

SAFE I Sustainable Architecture for Finance in Europe A cooperation of the Center for Financial Studies and Goethe University Frankfurt 


\section{Non-Technical Summary}

Technology spillover and international patent diffusion are important sources of economic growth. Moreover, international and domestic financial markets are highly developed and close-to-perfect in developed economies nowadays. Especially over the last decade, financial markets have become increasingly integrated. Asset returns are also typically quite highly correlated across countries. Another stylized fact in international macroeconomics is the robustly observed spread between the cross-country correlations of consumption growth to the one of output growth. Consumption growth is typically less correlated across countries than output growth.

So far, little is known about the equilibrium effects of technology spillover on asset prices and, in particular, on the cross-section of equity returns. This study develops a two-country endogenous growth economy with complete and frictionless financial markets that matches major stylized facts in international macroeconomics and provides a comprehensive analysis of cross-sectional and aggregate asset prices.

In the model, each country is populated by a single representative household, a single perfectly competitive final good firm, and a continuum of monopolistic intermediate good producers. The final good firm uses capital, labor, and a composite of intermediate goods to produce the respective country's final good. The production output is subject to both common and idiosyncratic productivity shocks affecting both countries simultaneously and only one country, respectively. The monopolistic intermediate good producers ("incumbents") each produce a single intermediate good. These incumbents can innovate on the quality of their products themselves or they can be displaced by new firms ("entrants") if these potential entrants make a successful innovation. Households consume both countries' consumption goods and display home bias for their domestic goods. The constant R\&D technology of incumbents and the stochastic technology of potential entrants use goods from both countries to capture endogenous technology spillover effects.

There are two important mechanisms at the core of this model. First, there is realistic competition between incumbents and potential entrants in innovations. Second, households and innovators share their risks internationally by using both final goods for consumption and R\&D. Due to these risk-sharing opportunities, innovations in one country thus induce a positive effect also on the productivity of the other country.

Three different versions of the model are analyzed. The initial model features a constant R\&D technology for entrants and no technology spillover. Next, technology spillover is added by allowing incumbents and entrants to use both goods for their R\&D technologies. Finally, the elasticity of entrants' R\&D is allowed to be stochastic. The first model only allows a small amount of final good trade and thus the households mainly resort to financial markets to share their risks. This induces a very high volatility of the exchange rate and negative spillover across countries in 
consumption dynamics driven by increased exports from the country experiencing a positive productivity shock to the other. This positive correlation between net exports and output is counterfactual and is resolved by adding technology spillover to the model. The increased quantities in good trade lead to a much smoother exchange rate and net exports now deteriorate in response to positive productivity news, consistent with the data. Furthermore, this model generates a considerable amount of positive spillover in $R \& D$ expenditures providing a realistic description of international technology diffusion. Stochastic R\&D technologies are needed to account for the observed fluctuations in the heterogeneous innovation process.

Regarding international asset pricing dynamics, the three model specifications yield different implications. The first model without technology spillover matches the moderate cross-country correlation of excess market returns but not the high correlation of risk-free rates in the data. The latter is resolved by all models with technology spillover at the cost of inducing too high a correlation of excess market returns. Excess returns of incumbents are positively correlated without technology spillover and highly negatively correlated with technology spillover. All models generate sizable risk premia due to technology innovations creating a volatile and persistent component in expected consumption growth.

To summarize, the novel technology spillover channel in the model provides a micro-foundation why returns, growth rates and macroeconomic quantities co-move across developed economies. 


\title{
International Endogenous Growth, Macro Anomalies, and Asset Prices
}

\author{
Patrick Grüning*
}

This version: January 22, 2015

\begin{abstract}
This paper studies a two-country production economy with complete and frictionless financial markets and international trade of final goods in which competition in R\&D leads to endogenous new firm creation and economic growth. Current monopolists ("incumbents") and potential new firms ("entrants") compete in developing patents domestically. I find that this induces negative spillover in consumption, i.e. home country's consumption decreases in response to positive productivity shocks in the foreign country. Second, there is positive spillover in $R \& D$ expenditures, i.e. home country's $R \& D$ expenditures increase in response to positive foreign productivity shocks, which is consistent with empirical evidence on international technology diffusion. Furthermore, the stylized fact in international macroeconomics that the cross-country correlation of consumption growth is significantly lower than the one of output growth is explained by the model. Fourth, net exports are negatively correlated with output as in the data. Fifth, the model matches the high comovement of the risk-free rates and stock returns across countries. Finally, the model produces a positive value premium.
\end{abstract}

Keywords: Innovation; Product Market Competition; Endogenous Growth; Longrun Risk; International Finance

JEL: E22; F31; G12; O30; O41

${ }^{*}$ Research Center SAFE and Department of Finance, Goethe-University, 60323 Frankfurt am Main, Germany. Phone: +49 (0) 69-798-30086. E-mail: gruening@safe.uni-frankfurt.de.

I am very grateful to colleagues from Goethe University Frankfurt and to Giuliano Curatola, Michael Donadelli, Lorenzo Garlappi, Adriana Grasso, Christoph Meinerding, Valentina Milano, and Christian Schlag for helpful comments and suggestions. All remaining errors are my own. I gratefully acknowledge research and financial support from the Research Center SAFE, funded by the State of Hessen initiative for research LOEWE. 


\section{Introduction}

Technology spillover and international patent diffusion have been identified as important sources of economic growth (see Coe, Helpman, and Hoffmaister (1997) and Santacreu (2014)). However, little is known about the equilibrium effects of technology spillover on asset prices and, in particular, the cross-section of equity returns. In this study, I develop a two-country endogenous growth economy with complete and frictionless financial markets that matches major stylized facts in international macroeconomics and that provides a comprehensive analysis of cross-sectional and aggregate asset prices. Major stylized facts in international macroeconomics include: (i) the cross-country correlations of macroeconomic quantities are moderate; (ii) asset markets highly comove; and (iii) asset markets are highly integrated nowadays among developed countries (see Rabanal, Rubio-Ramírez, and Tuesta (2011), Colacito and Croce (2013), and Fitzgerald (2012), respectively). Moreover, the cross-country correlation of consumption growth is significantly lower than the one of output growth (see Backus, Kehoe, and Kydland (1994)).

In the model, each country is populated by a representative household with recursive preferences, a competitive final good sector, and a monopolistic intermediate good sector. In the final good sector, a perfectly competitive representative final good firm uses capital, labor, and a composite of intermediate goods to produce the respective country's final good. The production output is subject to stochastic productivity shocks, which can be either restricted to one country ("idiosyncratic" shocks) or affect both countries simultaneously ("common" shocks). The intermediate good sector is populated by a continuum of monopolistic producers ("incumbents") each producing a single intermediate good. These incumbents can innovate on the quality of their products themselves or they can be displaced by new firms ("entrants") if these potential entrants make a successful innovation. ${ }^{1}$ Households consume an aggregate of the two consumption goods. Incumbents and potential entrants also use both consumption goods in their R\&D technologies.

\footnotetext{
${ }^{1}$ The continuing process of creation and destruction of companies due to technical obsolescence is a key feature of economic growth in developed countries. This process of creative destruction has already been emphasized by Schumpeter $(1934,1942)$.
} 
Finally, the entrants' technology is allowed to be stochastic, i.e. the elasticity parameter determining the efficiency of entrants' $R \& D$ expenditure is time-varying.

There are two important mechanisms at the core of my model. First, there is competition between incumbents and potential entrants in innovating intermediate goods. The level of the rate of radical innovation, i.e., the ratio of entrants' innovation probability to the total innovation probability in a given country, therefore has direct consequences on the patent value and consequently on aggregate quantities and asset prices. Second, households and innovators share their risks internationally by using both final goods for consumption and R\&D. Innovations in either country thus induce endogenous technology spillover effects which affect both domestic and foreign dynamics of growth rates and returns.

The model is calibrated to feature two symmetric equally-sized countries, which are highly developed to admit perfectly integrated financial markets. ${ }^{2}$ I study three different versions of the model. The initial model features a constant elasticity of entrants' R\&D technology and no technology spillover. Next, I add technology spillover by now allowing incumbents and entrants to use both goods in their R\&D technologies. Finally, the elasticity of entrants' R\&D is allowed to be stochastic.

I analyze implications for both macroeconomic quantities and asset prices. On the quantity side, the first model only allows limited risk-sharing via trading goods and thus the households mainly resort to financial markets to share their risks. This induces a very high volatility of the exchange rate and negative spillover across countries in consumption dynamics which are mainly driven by increased exports from the country experiencing a positive productivity shock to the other. This positive correlation between net exports and output is counterfactual and is resolved by adding technology spillover to the model. The increased quantities in goods trade lead to a much smoother exchange rate and net exports now deteriorate in response to positive productivity news, consistent with the data. Furthermore, this model generates a considerable amount of positive spillover in R\&D expenditures providing a realistic description of international technology diffusion. These

\footnotetext{
${ }^{2}$ This is a reasonable assumption for developed countries at least since the evidence in Fitzgerald (2012) suggests that risk-sharing via financial markets among developed economies is close to being optimal.
} 
two specifications of the model do not produce sufficient variation in the rate of radical innovation and therefore, I add stochasticity in entrants' R\&D technology as the next step. This can be interpreted as moving from a constant to a stochastic barrier to entry. While inheriting the dynamics of the model with a constant barrier to entry, this model specification additionally provides a close-to-perfect fit to the dynamics of the innovation process in the US. Moreover, shocks to the elasticity of entrants' R\&D are essentially not shared internationally which lowers the cross-country correlations of incumbents' and entrants' R\&D expenditure growth while keeping the correlation of aggregate R\&D expenditure at roughly the same level as before. In the data, aggregate R\&D expenditures are only moderately correlated across countries. The breakdown of aggregate R\&D expenditures into incumbents' and entrants' R\&D and their cross-country correlations using international data would be interesting to study but is beyond the scope of this study.

Regarding international asset pricing dynamics, these three model specifications also yield significantly different implications. First of all, endogenous growth coupled with recursive preferences generates a small persistent component in expected consumption growth which leads to significant risk premia in all models. The first model without technology spillover matches the moderate cross-country correlation of excess market returns but not the high correlation of risk-free rates in the data. The latter is resolved by all models with technology spillover at the cost of inducing too high a correlation of excess market returns. Excess returns of incumbents are positively correlated without technology spillover and highly negatively correlated with technology spillover.

This study is structured as follows. Section 2 provides a literature review. Next, I present my model in Section 3. It is followed by a discussion of the model's calibration and economic implications in Section 4. Section 5 concludes.

\section{Literature Review}

This study is related to several strands of the macroeconomic and finance literature. First, it builds on the literature on economic growth, which can be subdivided into the liter- 
ature on expanding product variety economies (see the seminal work of Romer (1990)) and Schumpeterian growth theory (see the seminal studies by Aghion and Howitt (1992) and Grossman and Helpman (1991)). Within the context of an expanding product variety model, in which growth is created by an increasing number of intermediate goods, Kung and Schmid (2013) show that endogenous growth endogenously creates a persistent component in expected consumption growth. They thus provide a microeconomic foundation of consumption-based models with long-run risks. ${ }^{3}$ Jinnai (2014) extends their model by accounting for the product cycle, i.e., the transition from monopoly to perfect competition in the intermediate good sector, and shows that this boosts risk premia by a factor of roughly two.

Schumpeterian growth theory, where innovations in product quality and not in the number of products create economic growth, allows for an empirically plausible positive relation between competition and growth in contrast to the aforementioned models with expanding product variety (see Aghion, Harris, Howitt, and Vickers (2001)). The dynamics of firm exit and entry are intensively studied in this literature. A firm enters with a new product using a superior, more productive technology and replaces the current firm ("creative destruction"). My model with innovating incumbents and potential entrants in each country is similar to the innovation dynamics in Acemoglu and Cao (2010), Akcigit and Kerr (2010), Klette and Kortum (2004), and Bena, Garlappi, and Grüning (2014). The latter study shows that Schumpeterian growth also creates the aforementioned persistent component in expected consumption growth and hence endogenous long-run risks. ${ }^{4}$ In contrast to these two studies, I study a two-country economy where R\&D expenditures are fueled by both consumption goods to capture R\&D spillovers (see the evidence in Coe, Helpman, and Hoffmaister (1997)).

\footnotetext{
${ }^{3}$ The long-run risks model introduced by Bansal and Yaron (2004) is one of the leading asset pricing models in finance. It has created a large literature centered around the empirical implications of the model and subsequent modifications of the theoretical model: Bansal, Kiku, and Yaron (2010), Bansal, Kiku, and Yaron (2012), and Colacito and Croce (2011). A critical study of the empirical implications of the long-run risks model is given in Beeler and Campbell (2012). Moreover, long-run productivity shocks have been introduced in production economies to jointly study asset prices and the business cycle: Croce (2014), Ai, Croce, and Li (2013), and Ai and Kiku (2013).

${ }^{4}$ A summary of the literature on Schumpeterian growth is provided by Acemoglu (2010) and Aghion and Howitt $(1998,2009)$.
} 
The second strand of literature my model relates to is the literature on international macroeconomics. It is closely related to recent papers using exogenous long-run productivity risks and recursive preferences in open two-country endowment and production economies, where households are allowed to share consumption risk internationally. To capture two famous empirical anomalies in international macroeconomics, ${ }^{5}$ Colacito and Croce (2013) compare a regime under financial autarky to a regime with complete markets. In Colacito, Croce, Ho, and Howard (2014), the differential reactions of countries with respect to short- and long-run producitivity news is studied. The model is carefully calibrated to account for the empirically observed international responses of capital and investment flows. However, the model does not account for the fact that output growth is internationally more correlated than consumption growth (the quantity anomaly of Backus, Kehoe, and Kydland (1994)). Colacito and Croce (2011) study exchange rates in a suitable exchange economy and explain the high variability of exchange rate growth relative to consumption growth ("exchange rate volatility puzzle"). Tretvoll (2013) explains the exchange rate volatility puzzle in a related production economy and provides a good fit to cross-country correlations of growth rates. A survey on asset pricing in multi-country economies is provided by Lewis (2011).

Third, the literature on trade and spillovers combines endogenous growth theory and multi-country production economies as I do in this study. The model in Gavazzoni and Santacreu (2014) is the closest to my model. They study a two-country endogenous growth economy with recursive preferences and adoption of technologies across countries to jointly explain the comovement in asset prices and macroeconomic dynamics. In contrast to my model, the households in their model only consume their respective country's final good and innovations are only driven by new firms as in Kung and Schmid (2013). This seems counterfactual to the empirical evidence since households in the US and especially in Europe consume goods from multiple countries. Moreover, their model ignores the importance of established firms for innovations, as documented by Bena, Garlappi, and Grüning

\footnotetext{
${ }^{5}$ Specifically, the following anomalies are explained: the correlation between consumption differentials and exchange rates has decreased over time (Backus and Smith (1993)) and the tendency of currencies in high real interest rate countries to appreciate has become more severe over time (Fama (1984)).
} 
(2014). To the best of my knowledge, my model is the first international endogenous growth model with heterogeneity in the innovation process. Liao and Santacreu (2013) show empirically and within the context of a multi-country model that the intensiveness of trade affects the cross-country correlation of business cycles. The adoption of foreign technologies and thus the diffusion of technology across countries is studied by Santacreu (2014). In particular, fast-growing developing countries seem to benefit from importing foreign technologies via trade (see Coe, Helpman, and Hoffmaister (1997)). This literature is quite silent about the asset pricing implications of technology spillover with the notable exception of Gavazzoni and Santacreu (2014). Ghironi and Melitz (2005) and Alessandria and Choi (2007) employ only international bond trading in their models.

\section{Model}

My model features two equally-sized countries which are called home and foreign in the following. Each country is populated by a representative household and two producing sectors. The first sector admits a perfectly competitive firm producing the final good of the respective country using labor, capital, and a composite of intermediate goods. The monopolistic intermediate good sector provides a continuum of intermediate goods for production in the final good sector. The monopolists ("incumbents") in this sector are threatened to be displaced by a more efficient firm entering the market ("entrant"). The households supply labor inelastically and hence do not make a leisure decision.

Financial markets are assumed to be complete and frictionless, both domestically and internationally. The countries thus represent developed economies with highly functional and integrated financial markets that admit perfect risk-sharing possibilities. Moreover, households and intermediate good producers can share their risks internationally by trading in good markets, i.e. households' consumption and incumbents' and potential entrants' effective R\&D expenditures are given as Cobb-Douglas aggregates of both final goods.

Domestic entrants are only allowed to enter the domestic intermediate good sector. Furthermore, incumbents only produce intermediate goods for the final good sector in their 
respective country. Therefore, competition in the intermediade good sector is restricted to one country. This is not as unrealistic as it sounds as only a relatively small fraction of firms actually exports (see, e.g., the evidence in Eaton, Kortum, and Kramarz (2004)). The assumption that R\&D expenditures are Cobb-Douglas aggregates over both final goods introduces a novel way to model technology spillover, which introduces a higher correlation of $R \& D$ expenditures across countries than in an economy where $R \& D$ expenditures are only comprised of the domestic final good. Hence, product innovations discovered in one country significantly and positively affect growth in the other country. Finally, the R\&D technology of entrants is allowed to be stochastic, i.e. the elasticity of entrants' R\&D innovation technology is assumed to follow an exogenous $\mathrm{AR}(1)$-process to better match the dynamics of the process of creative destruction in the data.

\subsection{Households}

The representative households in the home and foreign country have recursive preferences over a Cobb-Douglas aggregate of the final home and foreign good (see Epstein and Zin (1989) and Weil (1990)). Variables and parameters with index $h$ denote home country's quantities and those with index $f$ denote the foreign country's ones, respectively. Households' preferences in country $k=h, f$ are given by

$$
U_{t}^{(k)}=\left\{\left(1-\beta_{k}\right)\left(C_{t}^{(k)}\right)^{\frac{1-\gamma_{k}}{\theta_{k}}}+\beta_{k}\left(\mathbb{E}_{t}\left[\left(U_{t+1}^{(k)}\right)^{1-\gamma_{k}}\right]\right)^{\frac{1}{\theta_{k}}}\right\}^{\frac{\theta_{k}}{1-\gamma_{k}}}
$$

where $\gamma_{k}$ is the coefficient of relative risk aversion, $\beta_{k}$ the subjective time preference parameter, and $\psi_{k}$ the elasticity of intertemporal substitution. Finally, $\theta_{k}=\frac{1-\gamma_{k}}{1-\frac{1}{\psi_{k}}}$. The households choose the amount of the home final good, $\mathcal{Y}_{h, t}^{(k)}$, and of the foreign final good, $\mathcal{Y}_{f, t}^{(k)}$, for consumption to maximize lifetime utility. The resulting consumption bundle is given by

$$
C_{t}^{(k)}=\left(\mathcal{Y}_{k, t}^{(k)}\right)^{\phi_{\mathrm{C}, \mathrm{k}}}\left(\mathcal{Y}_{-k, t}^{(k)}\right)^{1-\phi_{\mathrm{C}, \mathrm{k}}}
$$


where $-k=f$ if $k=h$ and $-k=h$ if $k=f \cdot \phi_{\mathrm{C}, \mathrm{k}}>0.5$ captures home bias in consumption. Market clearing conditions dictate that the net output available in each country for consumption, $\mathcal{Y}_{t}^{(k)}, 6$ is allocated among both households, i.e.

$$
\mathcal{Y}_{t}^{(k)}=\mathcal{Y}_{k, t}^{(k)}+\mathcal{Y}_{k, t}^{(-k)}
$$

My assumption of complete and frictionless financial markets for trading final goods across countries implies that there is a complete set of Arrow-Debreu securities available to households in both countries. These claims are denoted by $Q_{t+1}\left(\chi_{t+1}\right)$ where $\chi_{t+1}$ is the state of the economy at time $t+1$. If a household holds one unit of $Q_{t+1}\left(\chi_{t+1}\right)$ between time $t$ and $t+1$, it receives one unit of the home country's final good if the economy is in state $\chi_{t+1}$ at time $t+1$ and zero otherwise. Country $k$ 's household's holdings of these assets are given by $A_{t+1}^{(k)}\left(\chi_{t+1}\right)$. The budget constraints of both households are therefore given by

$$
\begin{aligned}
& \mathcal{Y}_{h, t}^{(h)}+P_{t}^{(h)} \mathcal{Y}_{f, t}^{(h)}+\int_{\chi_{t+1}} A_{t+1}^{(h)}\left(\chi_{t+1}\right) Q_{t+1}\left(\chi_{t+1}\right)=A_{t}^{(h)}+\mathcal{Y}_{t}^{(h)} \\
& P_{t}^{(h)} \mathcal{Y}_{f, t}^{(f)}+\mathcal{Y}_{h, t}^{(f)}+\int_{\chi_{t+1}} A_{t+1}^{(f)}\left(\chi_{t+1}\right) Q_{t+1}\left(\chi_{t+1}\right)=A_{t}^{(f)}+P_{t}^{(h)} \mathcal{Y}_{t}^{(f)}
\end{aligned}
$$

$P_{t}^{(h)}\left(P_{t}^{(f)}\right)$ denotes the terms of trade or, equivalently, the price of the foreign (home) final good in home (foreign) final good units. These prices are determined by

$$
P_{t}^{(h)}=\frac{1-\phi_{C, h}}{\phi_{C, h}} \frac{\mathcal{Y}_{h, t}^{(h)}}{\mathcal{Y}_{h, t}^{(f)}}, \quad P_{t}^{(f)}=\frac{1}{P_{t}^{(h)}} .
$$

In Appendix A.1, I solve the international consumption allocation problem of these households. An important quantity in this context is the "pseudo" Pareto share $S_{t}$ measuring the relative performance of the home country to the foreign country. It is determined by

\footnotetext{
${ }^{6}$ Specifically, net output is given by final good output minus capital investment, final good input to production in the intermediate good sector, and total R\&D expenditures (see equation (16)).
} 
the following recursion (see equation (A9) in the appendix)

$$
S_{t}=S_{t-1} \frac{M_{t-1, t}^{(h)}}{M_{t-1, t}^{(f)}} \frac{C_{t}^{h}}{C_{t-1}^{h}} \frac{C_{t-1}^{(f)}}{C_{t}^{(f)}} .
$$

$S_{t}>1$ implies that the home country's household currently consumes more than the foreign country's one and is thus relatively richer. Moreover, since financial markets are complete exchange rate growth $\Delta e_{t}$ is given by

$$
\Delta e_{t}=\log \left(M_{t-1, t}^{(f)}\right)-\log \left(M_{t-1, t}^{(h)}\right)
$$

Finally, the stochastic discount factor expressed in units of the consumption aggregate, $C_{t}^{(k)}$, implied by above preferences can be expressed as

$$
\mathbb{M}_{t, t+1}^{(k)}=\frac{\partial U_{t}^{(k)} / \partial C_{t+1}^{(k)}}{\partial U_{t}^{(k)} / \partial C_{t}^{(k)}}=\beta_{k}^{\theta_{k}}\left(\frac{C_{t+1}^{(k)}}{C_{t}^{(k)}}\right)^{-\frac{\theta_{k}}{\psi_{k}}}\left(R_{c, t+1}^{(k)}\right)^{\theta_{k}-1}
$$

where $R_{c, t+1}^{(k)}=\frac{W_{c, t+1}^{(k)}}{W_{c, t}^{(k)}-C_{t}^{(k)}}$ is the return on consumption. Household's wealth $W_{c, t}^{(k)}$ is defined as the present value of future consumption, $W_{c, t}^{(k)}=\mathbb{E}_{t}\left[\sum_{s=1}^{\infty} M_{t, t+s}^{(k)} C_{t+s}^{(k)}\right]$. The stochastic discount factor expressed in units of country $k$ 's final good is given by

$$
\mathbb{M}_{t, t+1}^{(k), l o c}=\beta_{k}^{\theta_{k}}\left(\frac{C_{t+1}^{(k)}}{C_{t}^{(k)}}\right)^{1-\frac{\theta_{k}}{\psi_{k}}}\left(R_{c, t+1}^{(k)}\right)^{\theta_{k}-1}\left(\frac{\mathcal{Y}_{k, t+1}^{(k)}}{\mathcal{Y}_{k, t}^{(k)}}\right)^{-1}
$$

\subsection{Final Good Sectors}

I follow Kung and Schmid (2013) and Bena, Garlappi, and Grüning (2014) in modeling the final good sector, the intermediate good sector, and the R\&D technologies. There is a representative perfectly competitive firm in the final good sector of each country $k=h, f$ which produces the respective final good using capital $K_{t}^{(k)}$, labor $L_{t}^{(k)}$, and a composite of local intermediate goods $G_{t}^{(k)}$. Output is produced using the following Cobb-Douglas 
production technology

$$
Y_{t}^{(k)}=\left[\left(K_{t}^{(k)}\right)^{\alpha_{k}}\left(\Omega_{t}^{(k)} L_{t}^{(k)}\right)^{1-\alpha_{k}}\right]^{1-\xi_{k}}\left[G_{t}^{(k)}\right]^{\xi_{k}}
$$

where $\alpha_{k} \in(0,1)$ is the capital share, $\xi_{k} \in(0,1)$ is the share of intermediate goods and $\Omega_{t}^{(k)}=e^{z_{t}+a_{t}^{(k)}}$ is a productivity shock with two components. First, the common or world shock $z_{t}$ affects the productivity in both countries. It follows a strictly stationary $\operatorname{AR}(1)$ process

$$
z_{t}=\rho_{z} z_{t-1}+\varepsilon_{z, t}, \varepsilon_{z, t} \sim \mathcal{N}\left(0, \sigma_{z}^{2}\right)
$$

Second, the idiosyncratic shock $a_{t}^{(k)}$ is determined by a similar process

$$
a_{t}^{(k)}=\rho_{a, k} a_{t-1}^{(k)}+\varepsilon_{a, t}^{(k)}, \varepsilon_{a, t}^{(k)} \sim \mathcal{N}\left(0, \sigma_{a, k}^{2}\right) .
$$

These three productivity shocks are mutually independent. ${ }^{7}$ The existence of the common component induces a positive correlation in productivity levels in the two countries that is crucial to reconcile the empirical evidence of quite highly correlated output growth across countries with my model. ${ }^{8}$

I assume that in each country the intermediate good sector is composed of a continuum of measure one of intermediate good firms indexed by $i_{k} \in[0,1]$. Each intermediate good firm in each country produces one single intermediate good. The intermediate goods are then aggregated to the composite

$$
G_{t}^{(k)}=\left[\int_{0}^{1}\left(q_{i_{k}, \mathrm{t}}^{(\mathrm{k})}\right)^{1-\frac{1}{\nu_{k}}}\left(x_{i_{k}, \mathrm{t}}^{(\mathrm{k})}\right)^{\frac{1}{\nu_{k}}} d i_{k}\right]^{\nu_{k}}
$$

where $q_{i_{k}, \mathrm{t}}^{(\mathrm{k})}$ denotes the available quality of the respective intermediate good, $x_{i_{k}, \mathrm{t}}^{(\mathrm{k})}$ is the quantity of intermediate good $i_{k}$ produced and $\frac{\nu_{k}}{\nu_{k}-1}$ is the elasticity of substitution between any two intermediate goods. I assume $\nu_{k}>1$ to imply that an increasing quality in the intermediate goods leads to a more productive final good firm and thus fosters economic growth in the economy of the respective country. The final good sector only uses

\footnotetext{
${ }^{7}$ Equivalently, one could take out the common shock from the model and instead use only countryspecific productivity shocks that are correlated.

${ }^{8}$ See, e.g., the evidence on the correlation of TFP and output in Liao and Santacreu (2013)).
} 
local goods and intermediate goods cannot be exported to or imported from the other country. This allows me to clearly differentiate between the effects of productivity shocks on the final good sector and product innovations in the intermediate good sector. ${ }^{9}$

The final good firm in each country takes the pricing kernel of the country's household in local units $M_{t}^{(k), l o c}$ as given and chooses investment $I_{t}^{(k)}$, labor $L_{t}^{(k)}$, next period's capital $K_{t+1}^{(k)}$, and the quantity of intermediate good $i_{k}, x_{i_{k}, t}^{(\mathrm{k})}$, to maximize its value

$$
\max _{\left\{I_{t}^{(k)}, L_{t}^{(k)}, K_{t+1}^{(k)}, x_{i_{k}, \mathrm{t}}^{(\mathrm{k})}\right\}_{i_{k} \in[0,1] ; t \geq 0}} \mathbb{E}_{0}\left[\sum_{t=0}^{\infty} \mathbb{M}_{t}^{(k), l o c} D_{t}^{(k)}\right]
$$

where dividends are given by

$$
D_{t}^{(k)}=Y_{t}^{(k)}-I_{t}^{(k)}-\omega_{t}^{(k)} L_{t}^{(k)}-\int_{0}^{1} p_{i_{k}, \mathrm{t}}^{(\mathrm{k})} x_{i_{k}, \mathrm{t}}^{(\mathrm{k})} d i_{k},
$$

and where the price of intermediate good $i_{k}$ with quality $q_{i_{k}, \mathrm{t}}^{(\mathrm{k})}$ at time $t$ is denoted by $p_{i_{k}, \mathrm{t}}^{(\mathrm{k})}$. Capital accumulates according to

$$
K_{t+1}^{(k)}=\left(1-\delta_{k}\right) K_{t}^{(k)}+\Lambda^{(k)}\left(\frac{I_{t}^{(k)}}{K_{t}^{(k)}}\right) K_{t}^{(k)}
$$

where the capital depreciation rate is given by $\delta_{k}$ and the convex capital adjustment cost function is specified as in Jermann (1998). ${ }^{10}$ The optimization problem of the final good sector is standard and solved in Appendix A.2.

\footnotetext{
${ }^{9}$ This assumption is also broadly consistent with the fact that many manufacturing firms do not export at all and only serve domestic markets. Eaton, Kortum, and Kramarz (2004) report that the fraction of exporting manufacturing firms is only around $17.4 \%$ in France and $14.6 \%$ in the US, respectively. Moreover, Bernard, Eaton, Jensen, and Kortum (2003) show that exports in the manufacturing sector only represent a small share of total revenue for a large sample of countries in 1992. This measure is highly heterogeneous across countries and typically quite low (around $10 \%$ or below for most countries). ${ }^{10}$ Specifically, the functional form is $\Lambda^{(k)}\left(\frac{I_{t}^{(k)}}{K_{t}^{(k)}}\right)=\frac{\alpha_{1, k}}{1-\frac{1}{\zeta_{k}}}\left(\frac{I_{t}^{(k)}}{K_{t}^{(k)}}\right)^{1-\frac{1}{\zeta_{k}}}+\alpha_{2, k}$, where the constants are given by $\alpha_{1, k}=\left(Q_{s s}^{(k)}+\delta_{k}-1\right)^{\frac{1}{\zeta_{k}}}, \alpha_{2, k}=\frac{1}{1-\zeta_{k}}\left(Q_{s s}^{(k)}+\delta_{k}-1\right)$. The constant $Q_{s s}^{(k)}$ is chosen such that there are no adjustment costs in the deterministic steady state. The limiting cases $\zeta_{k} \rightarrow 0$ and $\zeta_{k} \rightarrow \infty$ represent infinitely costly adjustment and frictionless adjustment, respectively.
} 


\subsection{Intermediate Good sectors and R\&D Technologies}

There is a monopolistic intermediate good sector in each country, in which a continuum of incumbent firms produces intermediate goods for the respective final good sector. At the same time entrants deploy $R \& D$ giving them a chance to replace the respective incumbent and take over its monopoly.

\subsubsection{Incumbents}

At time 0 , intermediate good $i_{k}$ in country $k$ starts with quality $q_{i_{k}, 0}^{(k)}>0$ and is produced by an incumbent firm in country $k$ which holds a fully enforced patent on the initial quality. Incumbents need $\mu_{k}$ units of the final good to produce one unit of its respective intermediate good. Incumbent $i_{k}$ sets the price $p_{i_{k}, \mathrm{t}}^{(\mathrm{k})}$ to maximize its profits

$$
\pi_{i_{k}, \mathrm{t}}^{(\mathrm{k})}=\max _{\left\{p_{i_{k}, \mathrm{t}}^{(\mathrm{k})}\right\}}\left\{p_{i_{k}, \mathrm{t}}^{(\mathrm{k})} x_{i_{k}, \mathrm{t}}^{(\mathrm{k})}-\mu_{k} x_{i_{k}, \mathrm{t}}^{(\mathrm{k})}\right\}
$$

taking the demand schedule $x_{i_{k}, \mathrm{t}}^{(\mathrm{k})}$ for intermediate good $i_{k}$ of quality $q_{i_{k}, \mathrm{t}}^{(\mathrm{k})}$ determined by the final good firm as given (see equation (A15)). The optimal price is derived in Appendix A.2.

At each date $t$, the incumbent firm can improve its product quality by investing in R\&D. To capture technology spillover, the incumbent firm uses both the home and foreign country's final good in its innovation technology. ${ }^{11}$

If the incumbent spends $s_{\mathrm{I}, \mathrm{k}, i_{k}, \mathrm{t}}^{(\mathrm{k})} q_{i_{k}, \mathrm{t}}^{(\mathrm{k})}$ units of country $k$ 's and $s_{\mathrm{I}, \mathrm{k}, i_{k}, \mathrm{t}}^{(\mathrm{k})} q_{i_{k}, \mathrm{t}}^{(\mathrm{k})}$ of the other country's final good on R\&D to improve its intermediate good with quality $q_{i_{k}, \mathrm{t}}^{(\mathrm{k})}$, the probability of a successful product innovation by this incumbent is equal to $\Phi_{\mathrm{I}}^{(\mathrm{k})}\left(s_{\mathrm{I}, i_{k}, \mathrm{t}}^{(\mathrm{k})}\right)$, where ${ }^{12}$

$$
\Phi_{\mathrm{I}}^{(\mathrm{k})}\left(s_{\mathrm{I}, i_{k}, \mathrm{t}}^{(\mathrm{k})}\right)=\eta_{\mathrm{I}, \mathrm{k}}\left(s_{\mathrm{I}, i_{k}, \mathrm{t}}^{(\mathrm{k})}\right)^{\omega_{\mathrm{I}, \mathrm{k}}}, \quad s_{\mathrm{I}, i_{k}, \mathrm{t}}^{(\mathrm{k})}=\left(s_{\mathrm{I}, \mathrm{k}, i_{k}, \mathrm{t}}^{(\mathrm{k})}\right)^{\phi_{\mathrm{I}, \mathrm{k}}}\left(s_{\mathrm{I},-\mathrm{k}, i_{k}, \mathrm{t}}^{(\mathrm{k})}\right)^{1-\phi_{\mathrm{I}, \mathrm{k}}} .
$$

A successful innovation creates a patent to intermediate good $i_{k}$ with quality $\kappa_{\mathrm{I}, \mathrm{k}} q_{i_{k}, \mathrm{t}}^{(\mathrm{k})}$,

\footnotetext{
${ }^{11} \mathrm{R} \& \mathrm{D}$ and technology spillover have been identified as key sources of economic growth in, e.g., Coe, Helpman, and Hoffmaister (1997) and Santacreu (2014).

${ }^{12}$ This functional form of the R\&D technology $\Phi_{\mathrm{I}}^{(\mathrm{k})}$ has also been used by Comin, Gertler, and Santacreu (2009), Acemoglu and Cao (2010), and Kung and Schmid (2013), among others.
} 
where $\kappa_{\mathrm{I}, \mathrm{k}}>1$. The total amount of R\&D expenditure of country $k$ 's $(-k$ 's) final good by incumbent firms in country $k$ is

$$
S_{\mathrm{I}, \mathrm{k}, \mathrm{t}}^{(\mathrm{k})}=\int_{0}^{1} s_{\mathrm{I}, \mathrm{k}, i_{k}, \mathrm{t}}^{(\mathrm{k})} q_{i_{k}, \mathrm{t}}^{(\mathrm{k})} d i_{k}, \quad S_{\mathrm{I},-\mathrm{k}, \mathrm{t}}^{(\mathrm{k})}=\int_{0}^{1} s_{\mathrm{I},-\mathrm{k}, i_{k}, \mathrm{t}}^{(\mathrm{k})} q_{i_{k}, \mathrm{t}}^{(\mathrm{k})} d i_{k} .
$$

The level of technology capital in country $k$ is defined by the aggregate product quality in intermediate goods

$$
Q_{t}^{(k)}=\int_{0}^{1} q_{i_{k}, \mathrm{t}}^{(\mathrm{k})} d i_{k}
$$

These aggregate levels of technology capital in the home and foreign country are the key state variables in the model capturing endogenous economic growth.

\subsubsection{Entrants}

For each intermediate good $i_{k}$ in country $k$ at each date $t$, there is furthermore an infinite supply of atomistic entrants who deploy $R \& D$ in order to improve the intermediate good's quality and to take over the monopoly of the current incumbent due to the high productivity of this product. If all intermediate good $i_{k}$ entrants together spend $s_{\mathrm{E}, \mathrm{k}, i_{k}, \mathrm{t}}^{(\mathrm{k})} q_{i_{k}, \mathrm{t}}^{(\mathrm{k})}$ units of country $k$ 's and $s_{\mathrm{E},-\mathrm{k}, i_{k}, \mathrm{t}}^{(\mathrm{k})} q_{i_{k}, \mathrm{t}}^{(\mathrm{k})}$ units of the other country's final good on R\&D, the probability with which an entrant makes a discovery is $\hat{\Phi}_{\mathrm{E}, \mathrm{t}}^{(\mathrm{k})} \equiv s_{\mathrm{E}, i_{k}, \mathrm{t}}^{(\mathrm{k})} \Phi_{\mathrm{E}, \mathrm{t}}^{(\mathrm{k})}\left(s_{\mathrm{E}, i_{k}, \mathrm{t}}^{(\mathrm{k})}\right)$, where

$$
\Phi_{\mathrm{E}, \mathrm{t}}^{(\mathrm{k})}\left(s_{\mathrm{E}, i_{k}, \mathrm{t}}^{(\mathrm{k})}\right)=\eta_{\mathrm{E}, \mathrm{k}}\left(s_{\mathrm{E}, i_{k}, \mathrm{t}}^{(\mathrm{k})}\right)^{\omega_{\mathrm{E}, \mathrm{k}, \mathrm{t}}-1}, \quad s_{\mathrm{E}, i_{k}, \mathrm{t}}^{(\mathrm{k})}=\left(s_{\mathrm{E}, \mathrm{k}, i_{k}, \mathrm{t}}^{(\mathrm{k})}\right)^{\phi_{\mathrm{E}, \mathrm{k}}}\left(s_{\mathrm{E},-\mathrm{k}, i_{k}, \mathrm{t}}^{(\mathrm{k})}\right)^{1-\phi_{\mathrm{E}, \mathrm{k}}}
$$

and where the function $\Phi_{\mathrm{E}, \mathrm{t}}^{(\mathrm{k})}(\cdot)$ is chosen such that the innovation probability of entrants has the same functional form as the incumbents' one. ${ }^{13}$ However, there is one key difference. The elasticity of entrants' R\&D expenditure is time-varying and exogenously determined by the following stochastic process

$$
\omega_{\mathrm{E}, \mathrm{k}, \mathrm{t}+1}=\overline{\omega_{\mathrm{E}, \mathrm{k}}}\left(1-\rho_{\omega_{\mathrm{E}, \mathrm{k}}}\right)+\rho_{\omega_{\mathrm{E}, \mathrm{k}}} \omega_{\mathrm{E}, \mathrm{k}, \mathrm{t}}+\varepsilon_{t+1}^{\omega_{\mathrm{E}, \mathrm{k}}}, \quad \varepsilon_{t+1}^{\omega_{\mathrm{E}, \mathrm{k}}} \sim \mathcal{N}\left(0, \sigma_{\omega_{\mathrm{E}, \mathrm{k}}}^{2}\right)
$$

\footnotetext{
${ }^{13} \Phi_{\mathrm{E}, \mathrm{t}}^{(\mathrm{k})}\left(s_{\mathrm{E}, i_{k}, \mathrm{t}}^{(\mathrm{k})}\right)$ is taken as given by entrants in the optimization problem (15). See also the discussion in Appendix A.3.2.
} 
Hence, entrants' R\&D technology is stochastic and each country features a stochastic barrier to entry as the effectiveness with which potential entrants are successful is timevarying. This also introduces transitory heterogeneity among countries. The home country could feature a high barrier to entry, while simultaneously the foreign country's entrants face a low barrier to entry. Since $s_{\mathrm{I}, i_{k}, \mathrm{t}}^{(\mathrm{k})}, s_{\mathrm{E}, i_{k}, \mathrm{t}}^{(\mathrm{k})}<1$, higher values for $\omega_{\mathrm{I}, \mathrm{k}}$ and $\overline{\omega_{\mathrm{E}, \mathrm{k}}}$ represent lower efficiency in R\&D expenditures of incumbents and entrants, respectively. If an entrant makes a discovery, the intermediate good's quality increases to $\kappa_{\mathrm{E}, \mathrm{k}} q_{i_{k}, \mathrm{t}}^{(\mathrm{k})}$, where $\kappa_{\mathrm{E}, \mathrm{k}}>\kappa_{\mathrm{I}, \mathrm{k}}$, and the successful entrant becomes a new incumbent firm.

Entrants, by using both final goods, also enjoy the benefits of technology spillover, exactly as incumbents do. The total amount of R\&D expenditure of country $k$ 's ( $-k$ 's) final good by entrants in country $k$ is

$$
S_{\mathrm{E}, \mathrm{k}, \mathrm{t}}^{(\mathrm{k})}=\int_{0}^{1} s_{\mathrm{E}, \mathrm{k}, i_{k}, \mathrm{t}}^{(\mathrm{k})} q_{i_{k}, \mathrm{t}}^{(\mathrm{k})} d i_{k}, \quad S_{\mathrm{E},-\mathrm{k}, \mathrm{t}}^{(\mathrm{k})}=\int_{0}^{1} s_{\mathrm{E},-\mathrm{k}, i_{k}, \mathrm{t}}^{(\mathrm{k})} q_{i_{k}, \mathrm{t}}^{(\mathrm{k})} d i_{k} .
$$

\subsection{Valuation of Patents and R\&D Expenditures}

Incumbent firms invest the total amount $s_{\mathrm{I}, \mathrm{k}, i_{k}, \mathrm{t}}^{(\mathrm{k})} q_{i_{k}, \mathrm{t}}^{(\mathrm{k})}+P_{t}^{(k)} s_{\mathrm{I},-\mathrm{k}, i_{k}, \mathrm{t}}^{(\mathrm{k})} q_{i_{k}, \mathrm{t}}^{(\mathrm{k})}$ in R\&D and thus make a net profit of $\pi_{i_{k}, \mathrm{t}}^{(\mathrm{k})}-s_{\mathrm{I}, \mathrm{k}, i_{k}, \mathrm{t}}^{(\mathrm{k})} q_{i_{k}, \mathrm{t}}^{(\mathrm{k})}-P_{t}^{(k)} s_{\mathrm{I},-\mathrm{k}, i_{k}, \mathrm{t}}^{(\mathrm{k})} q_{i_{k}, \mathrm{t}}^{(\mathrm{k})}$ at time $t$. Due to the competition structure in the intermediate good sector, incumbent $i_{k}$ 's value in period $t+1$ is a random variable as of time $t$ and can take on three values. First, the incumbent might be displaced by an entrant with probability $\hat{\Phi}_{\mathrm{E}, \mathrm{t}}^{(\mathrm{k})}\left(s_{\mathrm{E}, i_{k}, \mathrm{t}}^{(\mathrm{k})}\right)$, where the incumbent takes the potential entrants' R\&D expenditure $s_{\mathrm{E}, i_{k}, \mathrm{t}}^{(\mathrm{k})}$ as given. In case of displacement, the incumbent's value drops to zero. Second, the incumbent might not be displaced but innovates itself. With probability $\Phi_{\mathrm{I}}^{(\mathrm{k})}\left(s_{\mathrm{I}, i_{k}, \mathrm{t}}^{(\mathrm{k})}\right)$, the incumbent improves on its product and the quality increases to $q_{i_{k}, t+1}^{(k)}=$ $\kappa_{\mathrm{I}, \mathrm{k}} q_{i_{k}, \mathrm{t}}^{(\mathrm{k})}$. Third, the incumbent might neither be displaced nor innovate itself. In this case, which happens with probability $1-\Phi_{\mathrm{I}}^{(\mathrm{k})}\left(s_{\mathrm{I}, i_{k}, \mathrm{t}}^{(\mathrm{k})}\right)-\hat{\Phi}_{\mathrm{E}, \mathrm{t}}^{(\mathrm{k})}\left(s_{\mathrm{E}, i_{k}, \mathrm{t}}^{(\mathrm{k})}\right)$, the quality depreciates to $q_{i_{k}, t+1}^{(k)}=\kappa_{\mathrm{D}, \mathrm{k}} q_{i_{k}, \mathrm{t}}^{(\mathrm{k})}$, where $\kappa_{\mathrm{D}, \mathrm{k}}<1$. This depreciation factor captures patent expiration and general obsolescence of products over time. Hence, the incumbent $i_{k}$ 's value function $v_{i_{k}, \mathrm{t}}^{(\mathrm{k})}$ 
solves the following Bellman equation

$$
\begin{aligned}
& v_{i_{k}, \mathrm{t}}^{(\mathrm{k})}\left(q_{i_{k}, \mathrm{t}}^{(\mathrm{k})}\right)=\max _{\left\{s_{\mathrm{I}, \mathrm{k}, i_{k}, \mathrm{t}}^{(\mathrm{k})} s_{\mathrm{I},-\mathrm{k}, i_{k}, \mathrm{t}}^{(\mathrm{k})}\right.}\left\{\pi_{i_{k}, \mathrm{t}}^{(\mathrm{k})}-s_{\mathrm{I}, \mathrm{k}, i_{k}, \mathrm{t}}^{(\mathrm{k})} q_{i_{k}, \mathrm{t}}^{(\mathrm{k})}-P_{t}^{(k)} s_{\mathrm{I},-\mathrm{k}, i_{k}, \mathrm{t}}^{(\mathrm{k})} q_{i_{k}, \mathrm{t}}^{(\mathrm{k})}\right. \\
& \left.+\mathbb{E}_{t}\left[\mathbb{M}_{t, t+1}^{(k), l o c}\left(\Phi_{\mathrm{I}}^{(\mathrm{k})} v_{i_{k}, \mathrm{t}+1}^{(\mathrm{k})}\left(\kappa_{\mathrm{I}, \mathrm{k}} q_{i_{k}, \mathrm{t}}^{(\mathrm{k})}\right)+\left(1-\Phi_{\mathrm{I}}^{(\mathrm{k})}-\hat{\Phi}_{\mathrm{E}, \mathrm{t}}^{(\mathrm{k})}\right) v_{i_{k}, \mathrm{t}+1}^{(\mathrm{k})}\left(\kappa_{\mathrm{D}, \mathrm{k}} q_{i_{k}, \mathrm{t}}^{(\mathrm{k})}\right)\right)\right]\right\} .
\end{aligned}
$$

From equations ( $A 16)$ and $(A 18)$, net profit is linear in quality. This implies $\pi_{i_{k}, \mathrm{t}}^{(\mathrm{k})}=\pi_{t}^{(k)} q_{i_{k}, \mathrm{t}}^{(\mathrm{k})}$. By focusing on a linear balanced growth path equilibrium, ${ }^{14}$ the following homogeneity properties emerge: $s_{\mathrm{I}, \mathrm{k}, i_{k}, \mathrm{t}}^{(\mathrm{k})} q_{i_{k}, \mathrm{t}}^{(\mathrm{k})}=s_{\mathrm{I}, \mathrm{k}, \mathrm{t}}^{(\mathrm{k})} q_{i_{k}, \mathrm{t}}^{(\mathrm{k})}, s_{\mathrm{I},-\mathrm{k}, i_{k}, \mathrm{t}}^{(\mathrm{k})} q_{i_{k}, \mathrm{t}}^{(\mathrm{k})}=s_{\mathrm{I},-\mathrm{k}, \mathrm{t}}^{(\mathrm{k})} q_{i_{k}, \mathrm{t}}^{(\mathrm{k})}, s_{\mathrm{E}, \mathrm{k}, i_{k}, \mathrm{t}}^{(\mathrm{k})} q_{i_{k}, \mathrm{t}}^{(\mathrm{k})}=s_{\mathrm{I}, \mathrm{k}, \mathrm{t}}^{(\mathrm{k})} q_{i_{k}, \mathrm{t}}^{(\mathrm{k})}$, and $s_{\mathrm{E},-\mathrm{k}, i_{k}, \mathrm{t}}^{(\mathrm{k})} q_{i_{k}, \mathrm{t}}^{(\mathrm{k})}=s_{\mathrm{E},-\mathrm{k}, \mathrm{t}}^{(\mathrm{k})} q_{i_{k}, \mathrm{t}}^{(\mathrm{k})}$. This implies $s_{\mathrm{I}, i_{k}, \mathrm{t}}^{(\mathrm{k})}=s_{\mathrm{I}, \mathrm{t}}^{(\mathrm{k})}, s_{\mathrm{E}, i_{k}, \mathrm{t}}^{(\mathrm{k})}=s_{\mathrm{E}, \mathrm{t}}^{(\mathrm{k})}$ as well. Furthermore, the incumbent's value is also linear in quality and thus $v_{i_{k}, \mathrm{t}}^{(\mathrm{k})}\left(q_{i_{k}, \mathrm{t}}^{(\mathrm{k})}\right)=v_{t}^{(k)} q_{i_{k}, \mathrm{t}}^{(\mathrm{k})}$ for all $t$ and $i_{k} \in[0,1]$. By plugging this into (13) and dividing by $q_{i_{k}, \mathrm{t}}^{(\mathrm{k})}$, the Bellman equation defining the incumbent's value, $v_{t}^{(k)}$, becomes

$$
\begin{aligned}
v_{t}^{(k)}= & \max _{\left\{s_{\mathrm{I}, \mathrm{k}, \mathrm{t}}^{(\mathrm{t})}, s_{\mathrm{I},-\mathrm{k}, \mathrm{t}}^{(\mathrm{k})}\right.}\left\{\pi_{t}^{(k)}-s_{\mathrm{I}, \mathrm{k}, \mathrm{t}}^{(\mathrm{k})}-P_{t}^{(k)} s_{\mathrm{I},-\mathrm{k}, \mathrm{t}}^{(\mathrm{k})}\right. \\
& \left.+\mathbb{E}_{t}\left[\mathbb{M}_{t, t+1}^{(k), l o c} v_{t+1}^{(k)}\left(\Phi_{\mathrm{I}}^{(\mathrm{k})}\left(s_{\mathrm{I}, \mathrm{t}}^{(\mathrm{k})}\right) \kappa_{\mathrm{I}, \mathrm{k}}+\left(1-\Phi_{\mathrm{I}}^{(\mathrm{k})}\left(s_{\mathrm{I}, \mathrm{t}}^{(\mathrm{k})}\right)-\hat{\Phi}_{\mathrm{E}, \mathrm{t}}^{(\mathrm{k})}\left(s_{\mathrm{E}, \mathrm{t}}^{(\mathrm{k})}\right)\right) \kappa_{\mathrm{D}, \mathrm{k}}\right)\right]\right\} .
\end{aligned}
$$

The first order conditions of this Bellman equation are supplied in Appendix A.3.1. Potential entrants enjoy free entry to the R\&D technology and thus they maximize the net present value of future profits achieved if they become incumbents

$$
\max _{\left\{s_{\mathrm{E}, \mathrm{k}, \mathrm{t}}^{(\mathrm{k})}, s_{\mathrm{E},-\mathrm{k}, \mathrm{t}}^{(\mathrm{t})}\right.}\left\{\hat{\Phi}_{\mathrm{E}, \mathrm{t}}^{(\mathrm{k})}\left(s_{\mathrm{E}, \mathrm{t}}^{(\mathrm{k})}\right) \kappa_{\mathrm{E}, \mathrm{k}} \mathbb{E}_{t}\left[\mathbb{M}_{t, t+1}^{(k), l o c} v_{t+1}^{(k)}\right]-s_{\mathrm{E}, \mathrm{k}, \mathrm{t}}^{(\mathrm{k})}-P_{t}^{(k)} s_{\mathrm{E},-\mathrm{k}, \mathrm{t}}^{(\mathrm{k})}\right\} .
$$

The first order conditions of this optimization problem are supplied in Appendix A.3.2.

\subsection{Resource Constraint}

To close the model, resource constraints in both countries need to be specified. Net output $\mathcal{Y}_{t}^{(k)}$ is final good output minus capital investment, final good input to production in the

\footnotetext{
${ }^{14}$ This conjecture follows Acemoglu and Cao (2010). The authors discuss that the linear balanced growth path equilibrium is the outcome of any equilibrium in their economy, although they cannot prove it if the R\&D technology of incumbents is non-linear. Nevertheless, I rely on this equilibrium concept although I am not able to prove these homogeneity properties in my model either.
} 
intermediate good sector, and total R\&D expenditures. Hence, it is given by

$$
\mathcal{Y}_{t}^{(k)}=Y_{t}^{(k)}-I_{t}^{(k)}-\mu_{k} X_{t}^{(k)}-S_{\mathrm{I}, \mathrm{k}, \mathrm{t}}^{(\mathrm{k})}-S_{\mathrm{I},-\mathrm{k}, \mathrm{t}}^{(\mathrm{k})}-S_{\mathrm{E}, \mathrm{k}, \mathrm{t}}^{(\mathrm{k})}-S_{\mathrm{E},-\mathrm{k}, \mathrm{t}}^{(\mathrm{k})} \cdot
$$

\subsection{Technology Capital and Equilibrium}

Since the incumbent's value $v_{t}^{(k)}$ and the R\&D expenditure bundles of incumbents and entrants are independent of the distribution of qualities $q_{i_{k}, \mathrm{t}}^{(\mathrm{k})}$ across incumbent firms, the dynamics of aggregate technology capital growth are given by

$$
\frac{Q_{t+1}^{(k)}}{Q_{t}^{(k)}}=\kappa_{\mathrm{D}, \mathrm{k}}+\left(\kappa_{\mathrm{I}, \mathrm{k}}-\kappa_{\mathrm{D}, \mathrm{k}}\right) \Phi_{\mathrm{I}}^{(\mathrm{k})}\left(s_{\mathrm{I}, \mathrm{t}}^{(\mathrm{k})}\right)+\left(\kappa_{\mathrm{E}, \mathrm{k}}-\kappa_{\mathrm{D}, \mathrm{k}}\right) \hat{\Phi}_{\mathrm{E}, \mathrm{t}}^{(\mathrm{k})}\left(s_{\mathrm{E}, \mathrm{t}}^{(\mathrm{k})}\right) .
$$

This equation determines the growth rate of technology capital and of the economy in the respective country. It depends on the level of $R \& D$ expenditures by incumbents and entrants. Over a period of time, $\Phi_{\mathrm{I}}^{(\mathrm{k})}$ intermediate good sectors experience an innovation by incumbents who increase quality by $\kappa_{\mathrm{I}, \mathrm{k}}$, another $\hat{\Phi}_{\mathrm{E}, \mathrm{t}}^{(\mathrm{k})}$ sectors experience an innovation by entrants who increase quality by $\kappa_{\mathrm{E}, \mathrm{k}}$ and displace the respective incumbents, and the remaining sectors' qualities depreciate by the factor $\kappa_{\mathrm{D}, \mathrm{k}}$. The growth rate is thus endogenously determined by heterogeneous innovations of incumbents and entrants.

The definition of the decentralized equilibrium in this economy is stated in Appendix A.4. The pricing kernels are used to price a number of assets. I exactly specify which assets are priced and how the resulting returns are computed in Appendix A.5. As each economy is growing, solving for the equilibrium requires normalizing the growing quantities by technology capital to make them stationary.

\section{Results}

I discuss how I calibrate the model and inspect the economic implications and intuition of three different specifications of the model in this section. For each calibration, the model 
is solved using third order perturbation methods. ${ }^{15}$

\subsection{Calibration}

Table 1 reports the quarterly parameters of three different model specifications. In the economy without R\&D spillover, the elasticity of entrants' R\&D is constant, i.e. $\omega_{\mathrm{E}, \mathrm{k}, \mathrm{t}} \equiv$ $\overline{\omega_{\mathrm{E}, \mathrm{k}}}$, and incumbents and entrants use only local goods for their R\&D expenditures. ${ }^{16}$ In the second calibration labeled "Technology Spillover" the R\&D expenditures of both incumbents and entrants are actual Cobb-Douglas aggregates of both final goods. For the last column labeled "Stochastic Barriers to Entry", I assume that $\omega_{\mathrm{E}, \mathrm{k}, \mathrm{t}}$ is not constant. Thus, the volatility in the stochastic process (11) is non-zero. In each calibration, countries are symmetric and thus have identical parameters.

The preference parameters are broadly in line with the literature on long-run risks (see Bansal and Yaron (2004)), i.e., the elasticity of intertemporal substitution (EIS), $\psi_{k}=1.1$, is above 1 , the risk aversion is large and set to $\gamma_{k}=10$, and the subjective discount factor is $\beta_{k}=\sqrt[4]{0.985} .^{17}$

The capital share and depreciation rate of physical capital are set to standard values used in the literature and have been taken from Kung and Schmid (2013), together with the remaining four parameters related to production. Specifically, $\alpha_{k}=0.35, \delta_{k}=0.02, \xi_{k}=$ $0.5, \nu_{k}=1.65, \mu_{k}=1$, and $\zeta_{k}=0.7$. My model thus features a high monopoly markup for intermediate good firms and a high degree of adjustment costs in physical capital. Furthermore, these parameter choices ensure balanced growth by satisfying the condition in equation (A19).

\footnotetext{
${ }^{15}$ These perturbation methods are implemented using Dynare++, version 4.4.3. All results are based on 5,000 simulations of the model with each sample being 250 quarters long after excluding the initial 50 quarters. For each simulation, I draw random sequences of the involved stochastic shocks and compute the state and policy variables using Dynare++'s Dynare_simul.m function.

${ }^{16}$ This economy represents a limiting case of the model presented in Section 3, i.e. one has to set the home bias parameter in the R\&D expenditure bundles to $\phi_{\mathrm{I}, \mathrm{k}}=\phi_{\mathrm{E}, \mathrm{k}}=1$.

${ }^{17}$ The elasticity of intertemportal substitution is chosen below the commonly used values of $1.5-2$ in the long-run risk literature as too high a motive for substitution would imply a negative correlation of quarterly growth rates across countries (in the data, however, this correlation is 0.36 as reported by Rabanal, Rubio-Ramírez, and Tuesta (2011)). See Section 4.2 and Colacito and Croce (2013) for a discussion on this matter.
} 
The autocorrelations of productivity shocks also follow Kung and Schmid (2013), i.e. $\rho_{z}=\rho_{a, k}=\sqrt[4]{0.95}$. The volatility of the country-specific shocks $\sigma_{a, k}$ and of the common productivity shock $\sigma_{z}$ are chosen to match the observed consumption growth volatility of $2.21 \%$ in the US between 1927 and 2008 (see Benzoni, Collin-Dufresne, and Goldstein (2011)) and the cross-country output growth correlation of 0.44 (see Rabanal, RubioRamírez, and Tuesta (2011)) across all calibrations. The relative size of the common component $z_{t}$ in the exogenous productivity processes determines output growth correlation in my model. The calibrated volatilities thus imply that the ratio $\frac{\sigma_{z}^{2}}{\sigma_{z}^{2}+\sigma_{a, k}^{2}}$ is 0.44 .

The R\&D related parameters are calibrated similarly to Bena, Garlappi, and Grüning (2014). The values $\kappa_{\mathrm{D}, \mathrm{k}}=0.966, \kappa_{\mathrm{E}, \mathrm{k}}=2.89$ and $\kappa_{\mathrm{I}, \mathrm{k}}=1.355$ are empirically estimated in this study and thus I choose the same values. Furthermore, I set $\eta_{\mathrm{I}, \mathrm{k}}=1.25$ and $\eta_{\mathrm{E}, \mathrm{k}}=0.15 . \omega_{\mathrm{I}, \mathrm{k}}$ and $\overline{\omega_{\mathrm{E}, \mathrm{k}}}$ are determined to match the observed mean consumption growth rate of $1.89 \%$ and average rate of radical innovation

$$
\Gamma_{t}=\frac{\hat{\Phi}_{\mathrm{E}, \mathrm{t}}^{(\mathrm{k})}}{\hat{\Phi}_{\mathrm{E}, \mathrm{t}}^{(\mathrm{k})}+\Phi_{\mathrm{I}}^{(\mathrm{k})}}
$$

of $10.67 \%$, as empirically documented by Bena, Garlappi, and Grüning (2014), in all calibrations. The details how these values are determined are given in Appendix B. For the first two economies, I assume that the elasticity of entrants' R\&D expenditure is constant and thus set $\rho_{\omega_{\mathrm{E}, \mathrm{k}}}=\sigma_{\omega_{\mathrm{E}, \mathrm{k}}}=0$. To match the autocorrelation and volatility of $\Gamma_{t}$ in the data, I choose $\rho_{\omega_{\mathrm{E}, \mathrm{k}}}=\sqrt[4]{0.9057}$ and $\sigma_{\omega_{\mathrm{E}, \mathrm{k}}}=0.251 \%$ in the stochastic-barrier-to-entry economy.

Following Colacito and Croce (2013), the home bias parameter for consumption is $\phi_{\mathrm{C}, \mathrm{k}}=$ 0.97. ${ }^{18}$ Finally, the home bias parameters in R\&D expenditures are set to $\phi_{\mathrm{I}, \mathrm{k}}=\phi_{\mathrm{E}, \mathrm{k}}=0.90$ for all economies except the one without R\&D spillover.

\footnotetext{
${ }^{18}$ Only about $3-5 \%$ of the US consumption bundle consists of foreign goods (see Erceg, Guerrieri, and Gust (2008)). Therefore, the assumption of a home bias of $97 \%$ is realistic given the empirical evidence.
} 


\subsection{The Economy without Technology Spillover}

This economy features only low trading turnover in good markets due to the high home bias in consumption and the absence of trading for R\&D expenditures. Financial markets, however, are perfectly integrated and allow households to efficiently share their risks via trading Arrow-Debreu securities. As documented first in the literature by Kung and Schmid (2013), endogenous growth coupled with recursive preferences induces a small persistent component in expected consumption growth endogenizing the long-run risk model of Bansal and Yaron (2004) in a production economy. A fraction of short-run productivity shocks is transformed into long-run shocks affecting the economy for a long period of time. The channel operates through positive innovations to total factor productivity (TFP) leading to higher R\&D expenditures which, in turn, lead to persistent increases in expected growth rates. Hence, the expected consumption growth volatility is substantial and amounts to $0.282 \%$ as reported in the first Panel of Table 2. Furthermore, the model replicates the expected consumption growth rate, consumption growth volatility, and the mean rate of radical innovation observed in the data due to calibration choices. Additionally, all other moments of the process of creative destruction are well matched with the exception of the volatility of the rate of radical innovation and the mechanically perfect correlation of incumbents' and entrants' innovation probabilities. Resolving the former issue is discussed in Section 4.4, where the R\&D technology of entrants is assumed to be stochastic. Consistent with the evidence in Broda and Weinstein (2010) that most innovations are undertaken in established firms, the fraction of total growth induced by entrants is only about one third. Therefore, the calibration of the process of creative destruction in my model is also in line with this empirical fact. Since there is no international trade of goods for R\&D expenditures, both incumbents' and entrants' $R \& D$ expenditure react strongly positively and persistently to domestic productivity shocks and only marginally positively to foreign shocks (see Figures 1 and 2 depicting the impulse response functions of home country's R\&D expenditures of incumbents and entrants, respectively). The small positive spillover from foreign productivity shocks is due to additional comovement in the pricing kernels as will become clear below. 
The model setup here is similar to the endowment economy in Colacito and Croce (2013), i.e. there is limited trading in consumption goods and correlated short- and long-run productivity shocks. In contrast to their model with exogenous long-run risks, the long-run risks in my model arise endogenously through heterogeneous $\mathrm{R} \& \mathrm{D}$ decisions by incumbents and entrants. However, the intuition carries over to my setup. These long-run risks are endogenously correlated due to comovement in the pricing kernels. A positive home idiosyncratic productivity shock induces positive long-run news and thus home household's continuation utility rises in anticipation of higher future consumption. This implies a lower marginal utility and by assumption of complete markets, the home currency depreciates and the exchange rate $\Delta e_{t}$ increases. Consequently, resources are reallocated to the country with the higher marginal utility, i.e. the foreign country. As a result of this, there are higher consumption good exports from the home to the foreign country which lead to an increase (decrease) in foreign (home) country's consumption. In other words, the share of world consumption of the home country and the Pareto share $S_{t}$ decrease.

In sum, this constitutes a negative spillover in consumption. It is depicted in the impulse reponse functions of Figure 3. The home consumption bundle $C_{t}^{(h)}$ decreases in response to home TFP shocks due to a strong decrease in imports from the foreign country $\mathcal{Y}_{f, t}^{(h)}$. The contribution of the home final good in home consumption $Y_{h, t}^{(h)}$ slightly increases, but less than proportionally to the increase in output due to higher exports.

To understand this, note that any shock in my model induces both short-run productivity news and endogenously positive long-run news at the same time. As decribed in Colacito, Croce, Ho, and Howard (2014), the households face a tradeoff after any innovation to productivity. On the one hand, resources should flow to the country with higher productivity (productivity channel). On the other hand, the resources should flow to the country with higher marginal utility (risk-sharing channel). ${ }^{19}$

The increase in consumption of the domestic good is thus due to the productivity channel

\footnotetext{
${ }^{19}$ Colacito, Croce, Ho, and Howard (2014) show that for long-run productivity news the risk-sharing channel dominates and hence, countries see their net exports deteriorate, and that for short-run productivity news the productivity channel is quantitatively more important and countries see an inflow of capital goods.
} 
since the home country has a higher productivity than the foreign country. Due to the risk-sharing channel detailed already above, the home household consumes more of both the home and the foreign final good in response to a foreign TFP shock. This is the consequence of the home country having the higher marginal utility and thus a part of the resources flow to the home country. The strong decrease in the home country's pricing kernel and the resulting increase in the exchange rate in response to home TFP shocks is depicted in Figure 4. Moreover, there is a small positive spillover in expected consumption growth, i.e. home consumption growth also slightly increases in response to foreign TFP shocks. This small positive spillover effect originates from the comovement of the pricing kernels, visible in Figure 4. The Pareto share $S_{t}$ drives this comovement by introducing a common endogenous component in the international consumption good allocation. Consequently, the valuation of patents, R\&D expenditures, and expected consumption growth comove across countries. Taken together, resources from home country's consumption are reallocated to domestic $R \& D$ expenditures and exports to the foreign country.

Since consumption reacts oppositely to output, investment or R\&D expenditures in response to idiosyncratic TFP shocks, within-country correlations of consumption with investment or output growth are only 0.30 and 0.28 , respectively. The still considerably positive correlation originates from the common shock in TFP affecting both countries at once and inducing an exogenous comovement of about 0.44 (which is the relative size of $\sigma_{z}$ to $\left.\sigma_{a, k}\right)$. Output and investment are perfectly correlated as these solely depend on domestic dynamics of TFP. The negative consumption spillover and the low marginal utility after domestic productivity shocks together induce a negative correlation of the rate of radical innovation with the market price of risk (i.e. the negative logarithm of the pricing kernel). This is so because the rate of radical innovation responses slightly negatively to domestic productivity shocks since incumbents' R\&D technology is slightly more linear than entrants' technology $\left(\omega_{\mathrm{I}, \mathrm{k}}>\overline{\omega_{\mathrm{E}, \mathrm{k}}}\right)$. Hence, $\Phi_{\mathrm{I}}^{(\mathrm{k})}$ responses slightly stronger to productivity shocks than $\hat{\Phi}_{\mathrm{E}, \mathrm{t}}^{(\mathrm{k})}$.

Table 3 reports domestic asset pricing moments. The excess returns are lower and the riskfree rate is higher than usual in endogenous growth models with recursive preferences due 
to the rather low EIS of 1.1. This lowers the market price of long-run risk substantially in relation to typical long-run risk models that employ values of 1.5-2 for the EIS. Furthermore, households have access to international consumption smoothing possibilities due to the availability of complete financial markets which further mitigates the risk in asset prices. Neverthess, the model reproduces the basic properties of long-run risk models: a moderate and smooth risk-free rate and substantial expected excess returns and return volatilities. The Sharpe Ratio of excess aggregate returns is about 39\%, which is close to the empirical evidence. There is a notable return spread between expected excess returns of the final good firm and of the incumbent firm. The spread amounts to about $1.6 \%$. The high adjustment costs for capital investment are responsible for the high expected excess return of the final good firm. Free entry in R\&D and the negative impact of entrants lead to rather low excess incumbent returns. If this spread is interpreted as a value premium, the model produces a largely positive value premium, as in the data. Interpreting this as a value premium seems reasonable as the final good firm has a higher book-to-market ratio than the incumbent firm in my model. ${ }^{20}$ Hence, the model replicates the empirical anomaly that firms with higher book-to-market ratios earn higher expected returns than firms with lower book-to-market ratios.

The substantial pressure for risk-sharing via financial markets lead to a quarterly exchange rate volatility of about $13.81 \%$, reported in Table 4, which is too high relative to the data. The EIS is quite low so that consumption smoothing motives via trading in international financial markets are strong. The low EIS is, however, needed to reconcile the quantity anomaly of Backus, Kehoe, and Kydland (1994), i.e. the observation that consumption growth is less correlated than output growth in the data. My model explains this anomaly by matching output growth correlation of 0.44 and only falling slightly short

\footnotetext{
${ }^{20}$ The book value of the final good firm is equal to capital $K_{t}$. The ratio of $K_{t}$ to the ex-dividend price of the final good firm, $V_{d, t}-D_{t}$, is about $98 \%$ in the stochastic steady state in my model. The book value of an incumbent firm is not straightforwardly defined. I define it as the profits generated by the patents without accounting for the growth options of incumbents. Applying appropriate risk-adjusted discounting by accounting for the obsolescence of patents and the displacement risk induced by entrants, I compute the book value of incumbents in the stochastic steady state as $\frac{\Pi_{s s}^{(k)}}{1-M_{s s}^{(k), l o c}\left(\kappa_{D}-\hat{\Phi}_{\mathrm{E}, \mathrm{ss}}^{(\mathrm{k})}\right)}$. The ratio of this quantity to the ex-dividend incumbent value, $v_{s s}^{(k)}-s_{\mathrm{I}, \mathrm{h}, \mathrm{ss}}^{(\mathrm{h})}-P_{s s}^{(h)} s_{\mathrm{I}, \mathrm{h}, \mathrm{ss}}^{(\mathrm{f})}$ is about $66 \%$. These values for the book-to-market ratios stay roughly constant across the other models in this section.
} 
of the consumption growth correlation in the data (0.28 in the model vs. 0.36 empirically). EIS $>1$ induces substitution motives for households, i.e. it is utility-enhancing for them to substitute consumption for R\&D expenditures to profit from higher future consumption. The resulting negative consumption spillover induces the correlation of cross-country consumption growth to be lower than the one of output growth. If the EIS was higher, the substitution effect would be too strong. The household would substitute too much consumption for R\&D expenditures after positive productivity news, eventually implying a negative cross-country correlation of consumption growth for an EIS high enough.

The small positive spillover in R\&D expenditures implies cross-country correlations of R\&D expenditure growth in excess of 0.44 (i.e. 0.49). Furthermore, expected consumption growth is a lot more correlated internationally than output growth due to the additional pricing kernel comovement induced by the Pareto share $S_{t}$, i.e. the cross-country correlation of pricing kernels is 0.79 .

This high comovement of the pricing kernels leads to highly correlated risk-free rates and excess returns. However, the correlation is not perfect and thus within an empirically reasonable range. The correlation of excess incumbent returns is 0.47 as R\&D expenditure growth is highly correlated. For the final good firm return, the correlation is slightly lower (0.41). As highly correlated incumbent $R \& D$ expenditures represent an outflow in aggregate dividends, $D_{a, t}^{(k)}$, defined as the sum of final good firm's dividends and incumbent's net profit in equation (A25), the correlation is only 0.38 and thus consistent with empirical evidence. The correlation of the risk-free rates is equal to 0.38 as well, which is below the value in the data. Since a positive productivity shock induces an increase in the net exports of consumption goods, $N X_{t}^{(h)}=\mathcal{Y}_{h, t}^{(f)}-P_{t}^{(h)} \mathcal{Y}_{f, t}^{(h)}$, the correlation of output and the net exports to GDP ratio is positive and equal to 0.18 , which is counterfactual given the data. Introducing technology spillover in the next section resolves this issue and it allows me to match the high cross-country correlation of risk-free rates. 


\subsection{Introducing Technology Spillover}

In this section, I study how adding technology R\&D spillovers and thus a higher degree of international connectedness affect the economic implications of the model analyzed in the last section by setting $\phi_{\mathrm{I}, \mathrm{k}}=\phi_{\mathrm{E}, \mathrm{k}}=0.90$ instead of 1 . The model is recalibrated to match again the mean and volatility of consumption growth, the mean rate of radical innovation, and the cross-country correlation of output growth by adjusting $\sigma_{a, k}, \sigma_{z}, \omega_{\mathrm{I}, \mathrm{k}}$, and $\overline{\omega_{\mathrm{E}, \mathrm{k}}}$. All other parameters are kept fixed.

Since the volatility of short-run productivity news is larger than the volatility of longrun risk ${ }^{21}$ the productivity channel, described in Section 4.2, is typically more important in this economy. However, net exports will be negatively correlated as in the data. The reason is that for import and export dynamics, due to the endogenous technology spillover mechanism, the risk-sharing channel quantitatively dominates due to the high importance of long-run news for R\&D expenditures as I will explain in more detail below.

By inspecting the impulse response functions of incumbents' and entrants' R\&D in Figures 1 and 2, one notices that there is an increased contribution of the home good in R\&D expenditures in response to a home TFP shock, i.e. increases in $s_{\mathrm{I}, \mathrm{h}, \mathrm{t}}^{(\mathrm{h})}$ and $s_{\mathrm{E}, \mathrm{h}, \mathrm{t}}^{(\mathrm{h})}$. However, there are lower imports from the foreign country, i.e. $s_{\mathrm{I}, \mathrm{f}, \mathrm{t}}^{(\mathrm{h})}$ and $s_{\mathrm{E}, \mathrm{f}, \mathrm{t}}^{(\mathrm{h})}$ decrease. In response to foreign TFP shocks, the home country imports more of the foreign good, whereas the contribution of the home good basically does not change. This means that net exports of final goods for R\&D deteriorate in response to domestic productivity news. This is due to the long-run component of these shocks. The short-run component of these shocks (productivity channel), however, implies that a significant fraction of the immediate increase in output is kept within the more productive country. In sum, the R\&D expenditure bundles of incumbents and entrants increase in response to both home and foreign productivity shocks. Hence, there is significant positive spillover in R\&D.

In Section 4.2, the technology spillover was also positive, but small. Adding technology

\footnotetext{
${ }^{21}$ This can be seen by noting that $\sqrt{\sigma_{z}^{2}+\sigma_{a, k}^{2}}>0.238 \%$, where the latter is the volatility of expected consumption growth reported in the third column of Table 2.
} 
spillover thus adds additional endogenous comovement between the countries. Hence, the cross-country correlations of R\&D expenditure growth rates, of the pricing kernels, and of expected consumption growth rates increase by values of up to $30 \%$ (see Table 4). The correlation of the net exports to GDP ratio with output is now significantly negative and broadly consistent with the data as domestic shocks imply an outflow of goods (see the lowest Panel of Table 4). ${ }^{22}$ Moreover, expected consumption growth increases in response to foreign shocks and by about one half of the response to domestic shocks. This represents a remarkable international diffusion of patents and is consistent with the empirical fact that many firms simultaneously file for patents in major developed countries, and that a significant fraction of growth is induced by foreign inventions (see the evidence in Eaton and Kortum (1999) and the references therein).

The increased importance of risk-sharing in good markets lowers the importance of risksharing via financial markets. Consequently, the exchange rate volatility drops by a factor of roughly 7 to $1.80 \%$, below the empirical counterpart. A lower degree of home bias in R\&D expenditures would therefore make the model able to match exchange rate data. Since the risk-sharing channel becomes quite unimportant for consumption, also here the productivity channel dominates and the home household keeps the major part of increased output after a home productivity shock within the country. Hence, the fraction of the home good's contribution to the home consumption bundle $\mathcal{Y}_{h, t}^{(h)}$ increases much more than in the economy of Section 4.2 (see Figure 3). The home country now experiences a small decrease (increase) in imports in response to a home (foreign) TFP shock. Stated differently, exports of consumption goods decrease in response to domestic productivity news. In sum, the consumption good allocation still features negative spillover, but in stark contrast to the economy without technology spillover the consumption bundle $C_{t}^{(h)}$ now increases in response to domestic shocks and decreases in response to foreign shocks. As a consequence, the within-country correlation of consumption growth with output or investment growth is close to unity. This also implies that exchange rate growth now decreases in response to domestic productivity shocks as can be seen from the lower Panel

${ }^{22}$ Total net exports of the home country are now: $N X_{t}^{(h)}=\mathcal{Y}_{h, t}^{(f)}+s_{\mathrm{I}, \mathrm{h}, \mathrm{t}}^{(\mathrm{f})}+s_{\mathrm{E}, \mathrm{h}, \mathrm{t}}^{(\mathrm{f})}-P_{t}^{(h)}\left(\mathcal{Y}_{f, t}^{(h)}+s_{\mathrm{I}, \mathrm{f}, \mathrm{t}}^{(\mathrm{h})}+s_{\mathrm{E}, \mathrm{f}, \mathrm{t}}^{(\mathrm{h})}\right)$. 
of Figure 4. The response is much weaker due to the aforementioned decreased incentives to share risks via financial markets.

The high degree of technology spillover does not change much the dynamics of R\&D expenditures whose moments are reported in the second Panel of Table 2. However, the correlation of the rate of radical innovation, $\Gamma_{t}$, and the market price of risk changes sign due to $\omega_{\mathrm{I}, \mathrm{k}}$ now being slightly smaller than $\overline{\omega_{\mathrm{E}, \mathrm{k}}} .23$ This induces the rate of radical innovation to go up in response to productivity news.

Asset pricing dynamics only slightly change due to better smoothing possibilities for households as reported in Table 3. The risk-free rate is slightly higher and less volatile. The risk premia decrease a bit. Since incumbents are more efficient in transforming productivity shocks to positive innovation probability news, the volatility of incumbents' R\&D expenditure growth is higher. This induces a more volatile demand for intermediate goods and thus the volatility of excess final good firm returns increases. Since incumbents' R\&D expenditure is an outflow to aggregate dividends, the volatility of the excess market returns decreases slightly. As incumbent profit becomes more volatile, the excess incumbent return increases by about one half relative to the economy without technology spillover and the volatility more then triples.

The technology-spillover economy inherits the success of matching the quantity anomaly of Backus, Kehoe, and Kydland (1994) as reported in the second Panel of Table 4. Due to the opposite directions of R\&D expenditure imports to domestic and foreign productivity shocks, the cross-country correlation of excess incumbent returns is significantly negative. Since R\&D expenditures are an outflow to aggregate dividends, this effect and the larger comovement of the pricing kernels induce a close-to-perfect cross-country correlation of excess market returns. Moreover, the excess final good firm return correlation slightly in-

\footnotetext{
${ }^{23}$ Since incumbents and entrants are required to use both goods for R\&D expenditures and thus their $\mathrm{R} \& \mathrm{D}$ technologies are less linear due to the assumption of Cobb-Douglas aggregates for $\mathrm{R} \& \mathrm{D}$ expenditures in this section, their efficiency would decline if both $\omega_{\mathrm{I}, \mathrm{k}}$ and $\overline{\omega_{\mathrm{E}, \mathrm{k}}}$ were kept fixed. Since the growth rate is fixed to $1.89 \%$, both incumbents and entrants however need to become more efficient (i.e. lower values of $\omega_{\mathrm{I}, \mathrm{k}}$ and $\left.\overline{\omega_{\mathrm{E}, \mathrm{k}}}\right)$. Morever, incumbents need to get even more efficient than entrants since the higher efficiency of entrants leads to higher displacement risk. To compensate incumbents for this risk, $\omega_{\mathrm{I}, \mathrm{k}}$ has to decrease more than $\overline{\omega_{\mathrm{E}, \mathrm{k}}}$.
} 
creases due to higher comovement of pricing kernels. Finally, the cross-country correlation of the risk-free rates in the model of 0.77 now closely matches the empirical evidence.

Appendix D provides comparative statics results on the equilibrium implications of different degrees of technology spillover by analyzing the model for different values of $\phi_{\mathrm{I}, \mathrm{k}}$ and $\phi_{\mathrm{E}, \mathrm{k}}$, i.e. verying home bias parameters for R\&D investments.

\subsection{Adding Stochastic Barriers to Entry (Full Model)}

Schumpeterian Growth models typically lead to a positive correlation of competition and growth (see Aghion, Harris, Howitt, and Vickers (2001)). The reason behind this is a positive correlation of entry and exit rates. An innovation of a potential entrant in my model leads to the exit of the current incumbent and the creation of a new firm, i.e. of an entrant. This leads to an increase in the technology capital level $Q_{t}^{(k)}$ due to the innovation size of entrants being relatively larger. A large empirical literature studies the dynamics of competition, growth, firm exit and entry. This literature confirms that this pattern of reallocation or creative destruction is productivity enhancing (see, e.g., Bartelsman, Haltiwanger, and Scarpetta (2004)). The displacement threat of entrants leads to higher labor productivity within incumbent firms. In other words, a high entry rate encourages growth and thus the cost of new firm creation is likely to be negatively correlated with output growth. Indeed, there is empirical evidence supporting this hypothesis. Loualiche (2014) identifies a systematic component that is present in firm entry rates and is not related to contemporaneous output growth. He interprets this as evidence that the cost of new firm creation varies independently from the productivity of existing firms. The correlation of this component with output growth is -0.4 (see Footnote 5 on page 2 in Loualiche (2014)).

To account for this empirical regularity in this section, I study how adding stochastic barriers to entry in both countries to the model of Section 4.3 affects the results. In order to do that, I assume that the elasticity of entrants' R\&D is stochastic and negatively correlated with both the idiosyncratic and the common productivity shock. These correlations 
are set to -0.4 to be consistent with the aforementioned empirical evidence. A negative shock to $\omega_{\mathrm{E}, \mathrm{k}, \mathrm{t}}$ implies that entrants in country $k$ become more efficient in their R\&D and, accordingly, that incumbents are more likely to be displaced. A positive shock to $\omega_{\mathrm{E}, \mathrm{k}, \mathrm{t}}$ can thus be intuitively attributed to signal a higher barrier to entry or a higher cost of new firm creation. If the correlations of shocks to $\omega_{\mathrm{E}, \mathrm{k}, \mathrm{t}}$ and both types of productivity shocks are negative, it is likely that a country experiences positive productivity shocks and negative shocks to $\omega_{\mathrm{E}, \mathrm{k}, \mathrm{t}}$ simultaneously. Hence, high competition coincides with good economic times on average.

As in the model and the empirical analysis of Loualiche (2014), the shocks to $\omega_{\mathrm{E}, \mathrm{k}, \mathrm{t}}$ represent an additional risk factor related to entry rates. Moreover, the shocks to $\omega_{\mathrm{E}, \mathrm{k}, \mathrm{t}}$ are independent across countries and thus there is transitory heterogeneity in countries' entry rates as one country might just feature a high barrier to entry while the other happens to have a low barrier to entry. The relatively high persistence of shocks to $\omega_{\mathrm{E}, \mathrm{k}, \mathrm{t}}$ gives rise to relatively long-lasting deviations from countries' symmetry and thus to periods of significantly different economic conditions with respect to entry dynamics in the countries. As also documented by Bena, Garlappi, and Grüning (2014), introducing stochastic barriers to entry does not change much the domestic dynamics of consumption and asset prices. This can also be seen from the impulse response functions in Figures 1-4. They hardly change compared to the technology-spillover economy. However, stochastic barriers to entry lead to a quarterly volatility of the rate of radical innovation of $2.19 \%$, consistent with US data (see the second Panel of Table 2). Furthermore, the volatilities of incumbents' and entrants' innovation probabilities increase by roughly one half and by a factor of three, respectively, which brings them close to the estimates in the data. Next, the correlation of incumbents' and entrants' innovation probability becomes negative due to the opposite effects of a shock to $\omega_{\mathrm{E}, \mathrm{k}, \mathrm{t}}$ on incumbents' and entrants' R\&D expenditures. This is depicted in Figures 5 and 6 . The effect of shocks to $\omega_{\mathrm{E}, \mathrm{k}, \mathrm{t}}$ on entrants' R\&D is more pronounced than on incumbents' R\&D implying that the positive effect on growth via lower costs of entry dominates the adverse effect on growth due to higher risk of displacement for incumbents. In the simulations, this effect will be amplified as positive 
productivity shocks and negative shocks to $\omega_{\mathrm{E}, \mathrm{k}, \mathrm{t}}$ are likely to happen simultaneously. Both shocks imply good news for entrants. Moreover, there is basically no technology spillover of a shock to $\omega_{\mathrm{E}, \mathrm{k}, \mathrm{t}}$ to the other country. Imports of goods for R\&D respond proportionally to the domestic good's contribution. Hence, resources are mainly reallocated domestically from entrants to incumbents in response to positive shocks to $\omega_{\mathrm{E}, \mathrm{k}, \mathrm{t}}$.

However, not all resources are redistributed from entrants to incumbents as depicted in Figure 7. A fraction is consumed by the home household. Furthermore, imports of goods for consumption slightly decrease and exports slightly increase. This implies higher expected consumption growth and a lower pricing kernel (see Figure 8). Since the foreign country experiences an increase in consumption due to higher exports from the home country, its pricing kernel decreases even more than the home country's one and the home currency appreciates (see the lower Panel of Figure 8). When $\omega_{\mathrm{E}, \mathrm{k}, \mathrm{t}}$ increases, the rate of radical innovation $\Gamma^{(k)}$ decreases precisely then, when the home country's pricing kernel deteriorates. Hence, shocks to $\omega_{\mathrm{E}, \mathrm{k}, \mathrm{t}}$ induce a negative correlation of $\Gamma^{(k)}$ and $-\log \left(M^{(k), l o c}\right)$. This is alleviated in part by assuming a negative correlation of shocks to $\omega_{\mathrm{E}, \mathrm{k}, \mathrm{t}}$ and productivity shocks. The likely simultaneous occurence of positive shocks to $\omega_{\mathrm{E}, \mathrm{k}, \mathrm{t}}$ and negative shocks to productivity lead to comovement of $\Gamma^{(k)}$ and $-\log \left(M^{(k), l o c}\right)$. Together with the positive correlation induced by common productivity shocks, the correlation of the rate of radical innovation and the market price of risk is 0.109 (see Table 2). Entrants' R\&D expenditures are riskier with negative correlations of shocks to $\omega_{\mathrm{E}, \mathrm{k}, \mathrm{t}}$ and productivity $\left(\rho_{a, \omega_{\mathrm{E}}, k}, \rho_{a, \omega_{\mathrm{E}}, k}<0\right)$. This is induced by the fact that both a low barrier to entry and high productivity represent good states for entrants and, with negative correlations, these good news happen simultaneously more often. Hence, the excess market return increases and becomes more volatile relative to the technology-spillover economy (see Table 3). At the same time, incumbents' R\&D becomes less risky and thus excess incumbent returns decrease. This also induces a lower cross-country correlation of these returns (see the fourth Panel of Table 4).

Other remarkable differences to the technology-spillover economy are visible in the crosscountry correlations of $R \& D$ expenditures (see the first Panel of Table 4). The absence 
of positive spillover in $R \& D$ expenditures for shocks to $\omega_{\mathrm{E}, \mathrm{k}, \mathrm{t}}$ induces pure noise in $\mathrm{R} \& \mathrm{D}$ expenditures across countries. This and the opposite effects of these shocks on incumbents' and entrants' R\&D expenditures diminish the positive cross-country correlations of R\&D expenditures induced by productivity shocks. Thus, the correlations of incumbents' and entrants' R\&D expenditures decrease from 0.78 in the technology-spillover economy to 0.25 for entrants and to -0.22 for incumbents. Since the level of aggregate R\&D expenditure in each country does not change much in response to shocks to $\omega_{\mathrm{E}, \mathrm{k}, \mathrm{t}}$, the cross-country correlation of aggregate $R \& D$ expenditure growth is not largely affected by these shocks and is equal to 0.73. The correlation of incumbents' R\&D expenditures becomes negative as a positive shock to $\omega_{\mathrm{E}, \mathrm{k}, \mathrm{t}}$ in one country leads to higher domestic R\&D expenditures of incumbents and, due to the negative correlation with the common productivity shock, it is likely that the foreign country will simultaneously experience a negative common productivity shock leading to lower R\&D expenditure of incumbents abroad. Entrants' R\&D expenditure on the other hand decreases if there is a positive shock to $\omega_{\mathrm{E}, \mathrm{k}, \mathrm{t}}$ and the likely contemporaneous negative productivity shock also leads to lower entrants' R\&D expenditures abroad. The correlation of entrants' R\&D expenditure thus remains positive.

\section{Conclusion}

This paper studies asset prices, macroeconomic quantities and risk-sharing dynamics in a two-country endogenous growth economy with technology spillover and stochastic barriers to entry, where innovations are driven by heterogeneous innovations of competing firms.

Endogenous growth coupled with recursive preferences and technology spillover generates a small persistent component in expected consumption growth inducing realistic asset pricing dynamics by means of endogenous long-run risks. On the one hand, there is positive spillover in R\&D expenditures implying that shocks to the innovation process are partly transmitted from the home to the foreign country. This creates a realistic technology diffusion process that furthermore allows the model to match the observed high comovement of risk-free rates across countries in the data. On the other hand, productivity shocks spill 
over to the other country with the opposite sign for consumption. Modeling a stochastic barrier to entry allows the model to almost perfectly match the empirical evidence on the cross-sectional properties of the innovation process. Taking out this technology spillover channel induces a much higher exchange rate volatility, a too low cross-country correlation of risk-free rates, and a realistic correlation of equity returns. Finally, I explain the quantity anomaly of Backus, Kehoe, and Kydland (1994): consumption growth is internationally less correlated than output growth in all three model specifications.

Taken together, this study shows that international technology spillovers are an important channel for explaining comovement of innovations and asset prices. Higher international comovement of economic growth and asset prices would be the likely consequence of policies that reduce international barriers in $\mathrm{R} \& \mathrm{D}$. Moreover, stochastic barriers to entry affect domestic R\&D dynamics and cross-country correlations of incumbents' and entrants' R\&D expenditures. Policies designed to change the costs of entry in a country in a world with international technology spillover thus also affect R\&D dynamics abroad. 


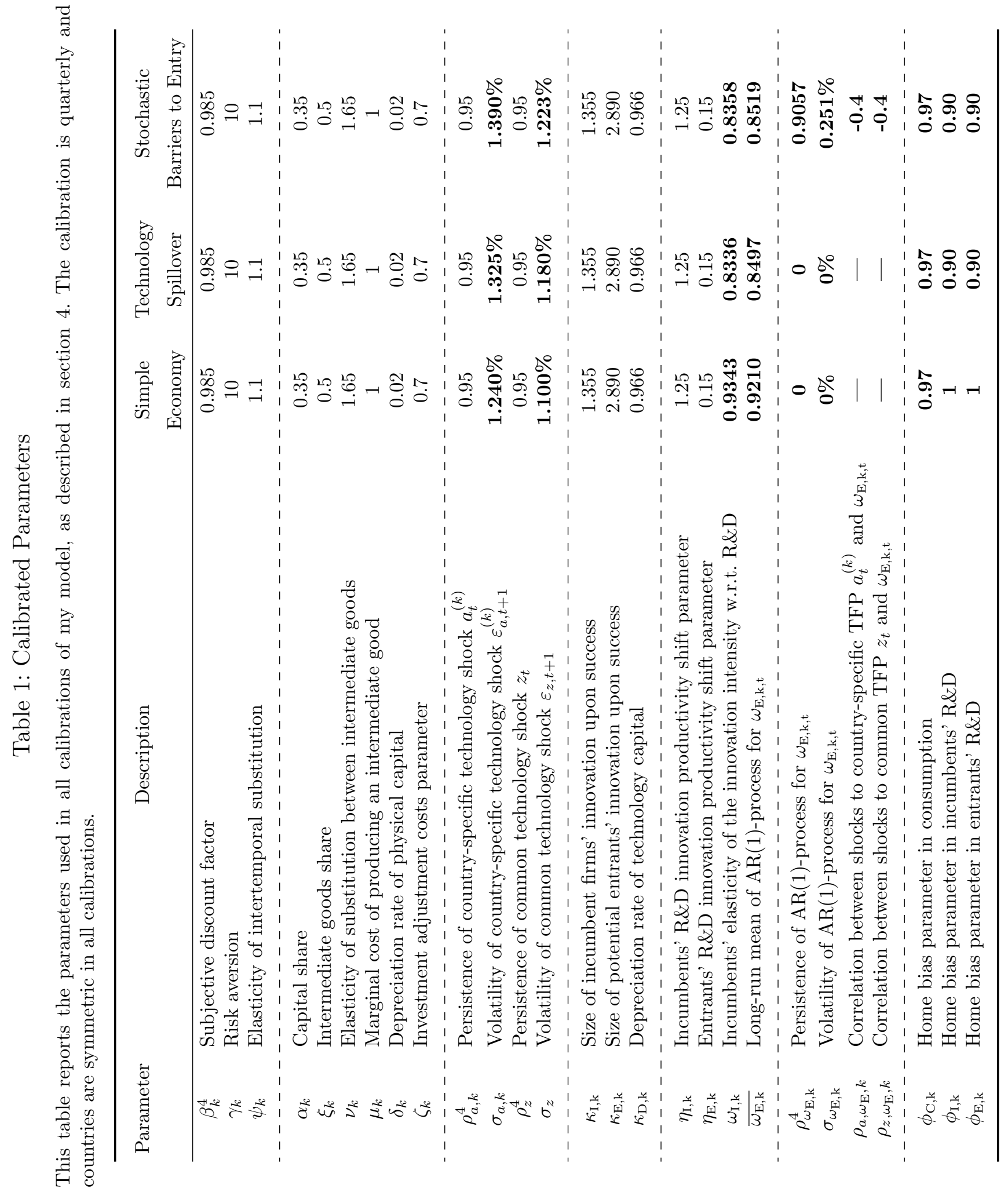


Table 2: Country-Specific Macro Quantities

This table reports the simulated moments for consumption dynamics, innovation dynamics, and withincountry correlations of macroeconomic quantities of the model developed in Section 3 and the calibrations reported in Table 1. The model is simulated 5,000 times with each sample being 250 quarters long after excluding the initial 50 quarters. The moments of the model and the data are annual in the consumption panel and quarterly in all other panels. Details on the sources for the values in the data column are provided in Appendix C.

\begin{tabular}{|c|c|c|c|c|}
\hline & Data & $\begin{array}{l}\text { Economy w/o } \\
\text { R\&D Spillover }\end{array}$ & $\begin{array}{l}\text { Technology } \\
\text { Spillover }\end{array}$ & $\begin{array}{c}\text { Stochastic Barriers } \\
\text { To Entry }\end{array}$ \\
\hline & \multicolumn{4}{|c|}{ Consumption } \\
\hline $\mathbb{E}\left[\Delta c^{(k)}\right]$ & $1.89 \%$ & $1.89 \%$ & $1.89 \%$ & $1.89 \%$ \\
\hline$\sigma_{\Delta c^{(k)}}$ & $2.21 \%$ & $2.21 \%$ & $2.21 \%$ & $2.21 \%$ \\
\hline \multirow[t]{2}{*}{$\sigma\left(\mathbb{E}_{t}\left[\Delta c_{t+1}^{(k)}\right]\right)$} & - & $0.282 \%$ & $0.238 \%$ & $0.243 \%$ \\
\hline & \multicolumn{4}{|c|}{ Process of Creative Destruction } \\
\hline $\mathbb{E}\left[\Gamma_{t}^{(k)}\right]$ & $10.67 \%$ & $10.67 \%$ & $10.67 \%$ & $10.67 \%$ \\
\hline $\mathbb{E}\left[\Phi_{I}^{(\mathrm{k})}\right]$ & $5.58 \%$ & $6.27 \%$ & $6.26 \%$ & $6.29 \%$ \\
\hline $\mathbb{E}\left[\hat{\Phi}_{\mathrm{E}, \mathrm{t}}^{(\mathrm{k})}\right]$ & $0.68 \%$ & $0.75 \%$ & $0.75 \%$ & $0.74 \%$ \\
\hline$\sigma_{\Gamma_{t}^{(k)}}$ & $2.19 \%$ & $0.10 \%$ & $0.06 \%$ & $2.19 \%$ \\
\hline$\sigma_{\Phi_{\mathrm{I}}^{(\mathrm{k})}}$ & $0.50 \%$ & $0.38 \%$ & $0.30 \%$ & $0.46 \%$ \\
\hline$\sigma_{\hat{\Phi}_{\mathrm{E}, \mathrm{t}}^{(\mathrm{k})}}$ & $0.18 \%$ & $0.04 \%$ & $0.04 \%$ & $0.13 \%$ \\
\hline$A C 1\left(\Gamma_{t}^{(k)}\right)$ & 0.969 & 0.966 & 0.973 & 0.969 \\
\hline $\operatorname{corr}\left(\Phi_{\mathrm{I}}^{(\mathrm{k})}, \hat{\Phi}_{\mathrm{E}, \mathrm{t}}^{(\mathrm{k})}\right)$ & 0.760 & 1.000 & 1.000 & -0.633 \\
\hline \multirow[t]{2}{*}{$\operatorname{corr}\left(\Gamma_{t},-\log \left(M^{(k), l o c}\right)\right)$} & - & -0.212 & 0.190 & 0.109 \\
\hline & \multicolumn{4}{|c|}{ Entrants' Growth Share } \\
\hline \multirow[t]{2}{*}{$\frac{\mathbb{E}\left[\Phi_{\mathrm{E}, \mathrm{t}}^{(\mathrm{k})}\right]\left(\kappa_{\mathrm{E}, \mathrm{k}}-\kappa_{\mathrm{D}, \mathrm{k}}\right)}{1+\mathbb{E}\left[\Delta c^{(k)}\right] / 4-\kappa_{\mathrm{D}, \mathrm{k}}}$} & - & $37.05 \%$ & $37.11 \%$ & $36.81 \%$ \\
\hline & \multicolumn{4}{|c|}{ Correlation of Growth Rates } \\
\hline $\operatorname{corr}\left(\Delta c^{(k)}, \Delta y^{(k)}\right)$ & 0.84 & 0.30 & 0.99 & 0.99 \\
\hline $\operatorname{corr}\left(\Delta c^{(k)}, \Delta i^{(k)}\right)$ & - & 0.28 & 0.99 & 0.99 \\
\hline $\operatorname{corr}\left(\Delta y^{(k)}, \Delta i^{(k)}\right)$ & 0.91 & 1.00 & 1.00 & 1.00 \\
\hline
\end{tabular}




\section{Table 3: Asset Prices}

This table reports the simulated moments for the risk-free rate, the excess return on consumption, the excess market return, the excess final good firm return, and the excess return of incumbents of the model developed in Section 3 and the calibrations reported in Table 1. The model is simulated 5,000 times with each sample being 250 quarters long after excluding the initial 50 quarters. The moments of the model and the data are annual. Returns in the model are levered following Boldrin, Christiano, and Fisher (2001). Details on the sources for the values in the data column are provided in Appendix C.

\begin{tabular}{|c|c|c|c|c|}
\hline & Data & $\begin{array}{l}\text { Economy w/o } \\
\text { R\&D Spillover }\end{array}$ & $\begin{array}{l}\text { Technology } \\
\text { Spillover }\end{array}$ & $\begin{array}{c}\text { Stochastic Barriers } \\
\text { To Entry }\end{array}$ \\
\hline & \multicolumn{4}{|c|}{ Risk-free Rate } \\
\hline \multirow{3}{*}{$\begin{array}{r}\mathbb{E}\left[r_{f}^{(k)}\right] \\
\sigma_{r_{f}^{(k)}}\end{array}$} & $0.64 \%$ & $2.52 \%$ & $2.56 \%$ & $2.57 \%$ \\
\hline & $3.84 \%$ & $0.54 \%$ & $0.44 \%$ & $0.45 \%$ \\
\hline & \multicolumn{4}{|c|}{ Return on Consumption } \\
\hline \multirow{3}{*}{$\begin{array}{r}\mathbb{E}\left[r_{c}^{(k)}-r_{f}^{(k)}\right] \\
\sigma_{r_{c}^{(k)}-r_{f}^{(k)}}^{(k)}\end{array}$} & - & $1.30 \%$ & $1.23 \%$ & $1.22 \%$ \\
\hline & - & $3.59 \%$ & $3.61 \%$ & $3.61 \%$ \\
\hline & \multicolumn{4}{|c|}{ Market Return } \\
\hline \multirow{3}{*}{$\begin{array}{r}\mathbb{E}\left[r_{a}^{(k)}-r_{f}^{(k)}\right] \\
\sigma_{r_{a}^{(k)}-r_{f}^{(k)}}\end{array}$} & $6.73 \%$ & $1.37 \%$ & $1.30 \%$ & $1.46 \%$ \\
\hline & $20.52 \%$ & $3.52 \%$ & $3.38 \%$ & $3.89 \%$ \\
\hline & \multicolumn{4}{|c|}{ Final Good Firm Return } \\
\hline \multirow{3}{*}{$\begin{array}{r}\mathbb{E}\left[r_{d}^{(k)}-r_{f}^{(k)}\right] \\
\sigma_{r_{d}^{(k)}-r_{f}^{(k)}}\end{array}$} & - & $1.81 \%$ & $1.59 \%$ & $1.61 \%$ \\
\hline & - & $4.62 \%$ & $4.83 \%$ & $4.94 \%$ \\
\hline & \multicolumn{4}{|c|}{ Incumbent Firm Return } \\
\hline $\mathbb{E}\left[r_{I}^{(k)}-r_{f}^{(k)}\right]$ & - & $0.20 \%$ & $0.31 \%$ & $0.03 \%$ \\
\hline$\sigma_{r_{I}^{(k)}-r_{f}^{(k)}}$ & - & $0.49 \%$ & $1.51 \%$ & $1.57 \%$ \\
\hline
\end{tabular}




\section{Table 4: International Quantities}

This table reports the simulated moments for exchange rate growth, cross-country correlations of macroeconomic quantities, expected consumption growth rates, the pricing kernels, and returns, and net exports dynamics of the model developed in Section 3 and the calibrations reported in Table 1 . The model is simulated 5,000 times with each sample being 250 quarters long after excluding the initial 50 quarters. The moments of the model and the data are annual for the correlation of R\&D expenditure growth rates due to data availability. The moments are quarterly otherwise. Furthermore, the value for the cross-country correlation of aggregate excess returns in the data column is compiled from a study using monthly returns. Returns in the model are levered following Boldrin, Christiano, and Fisher (2001). Details on the sources for the values in the data column are provided in Appendix C.

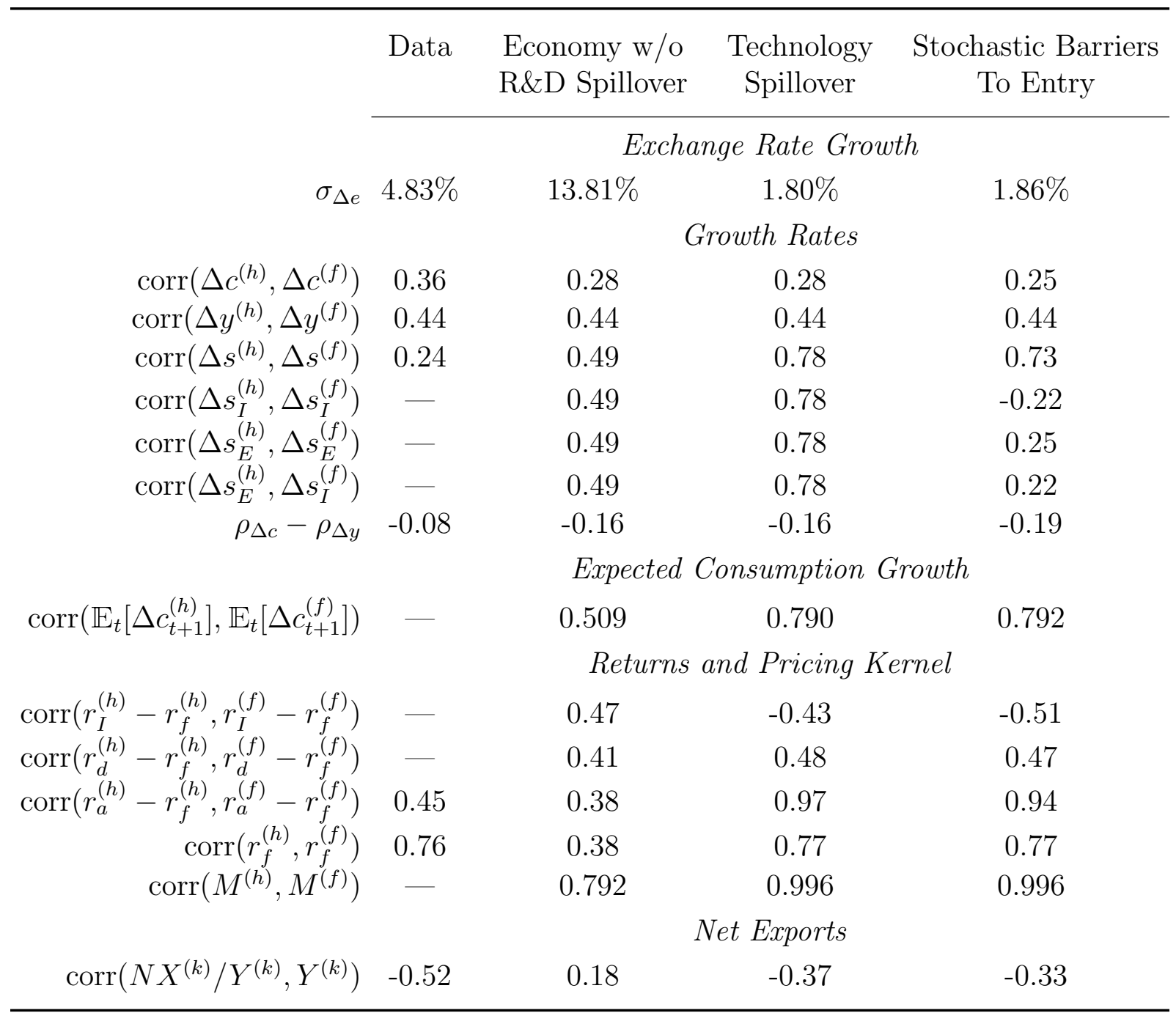




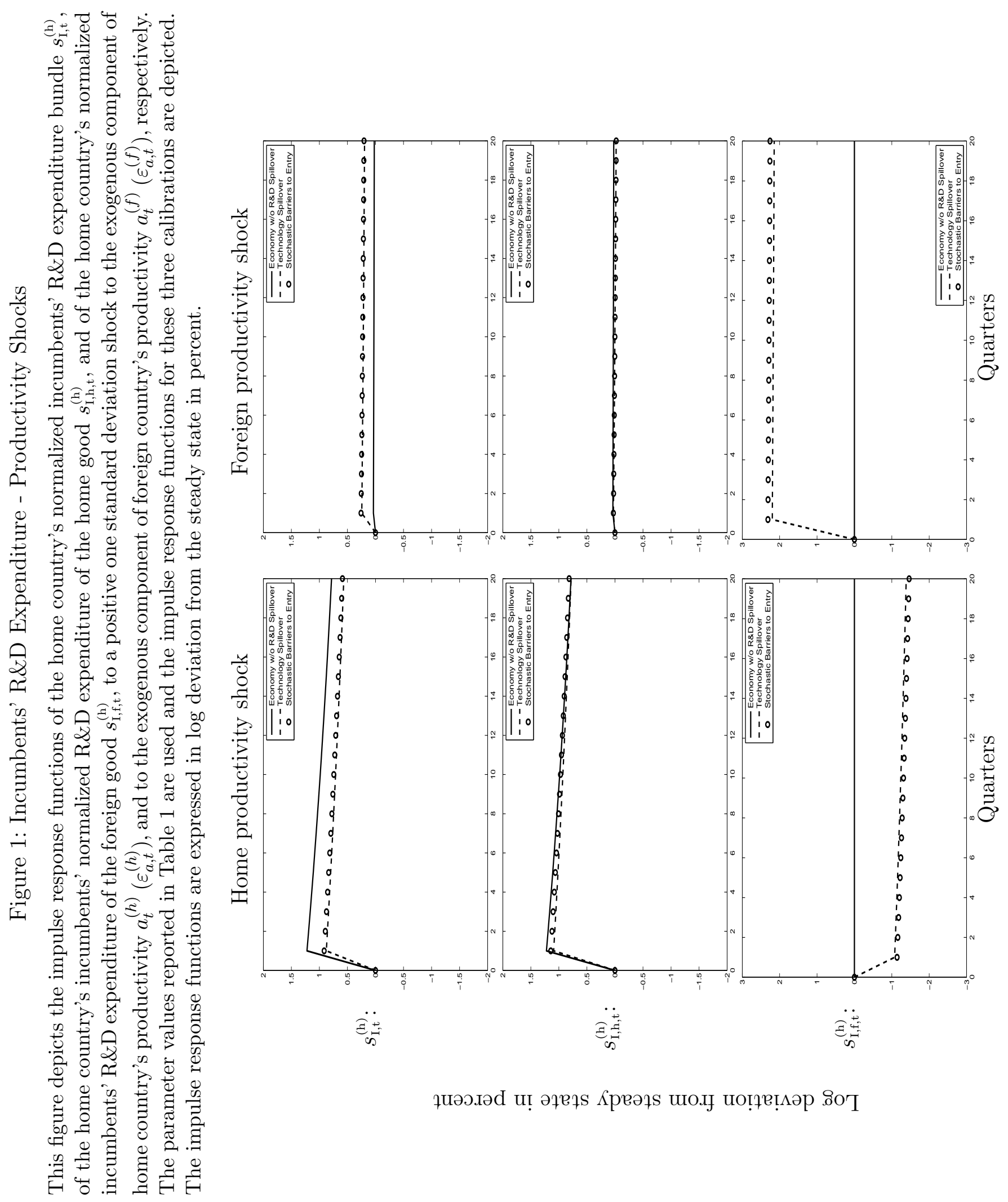




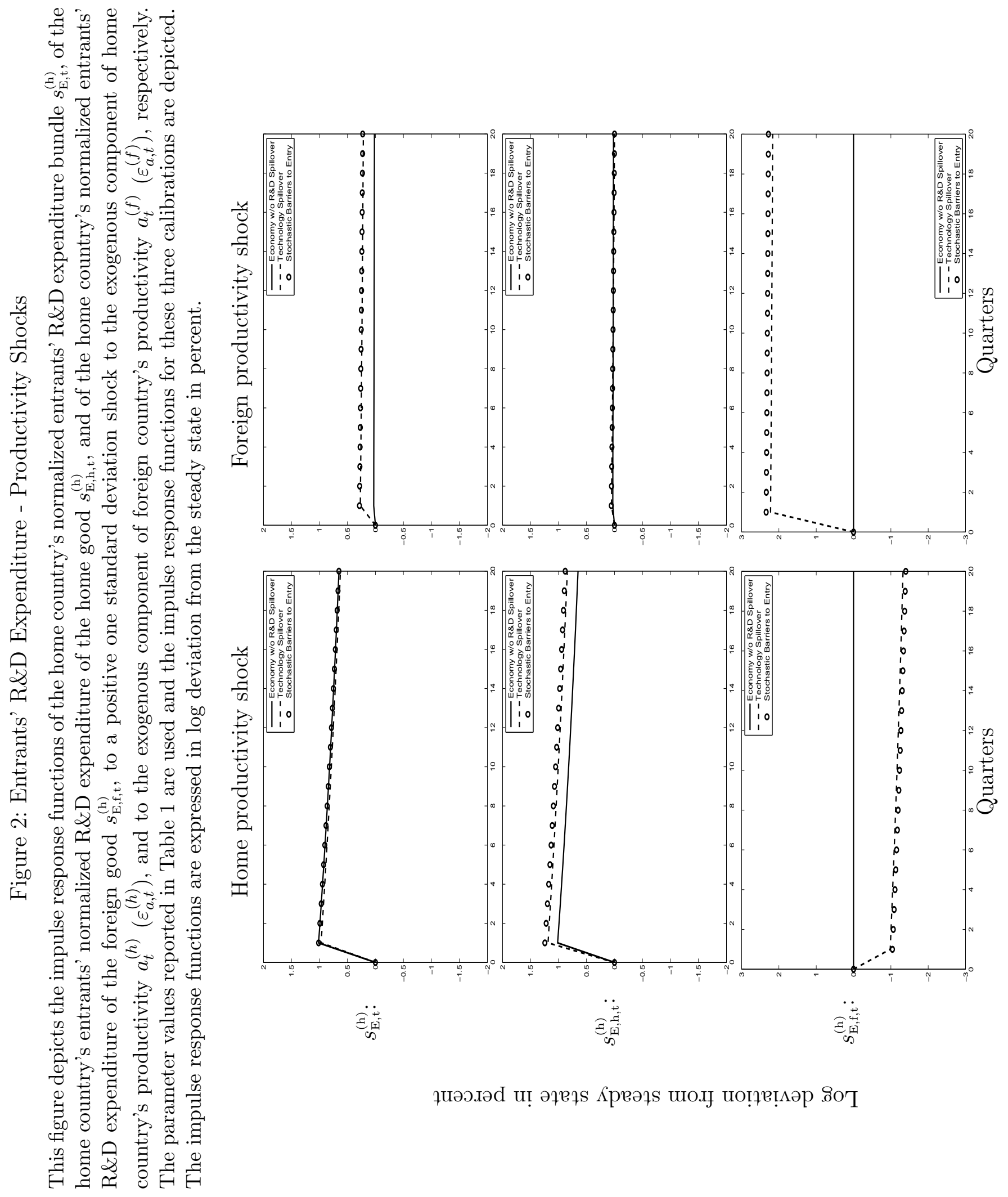




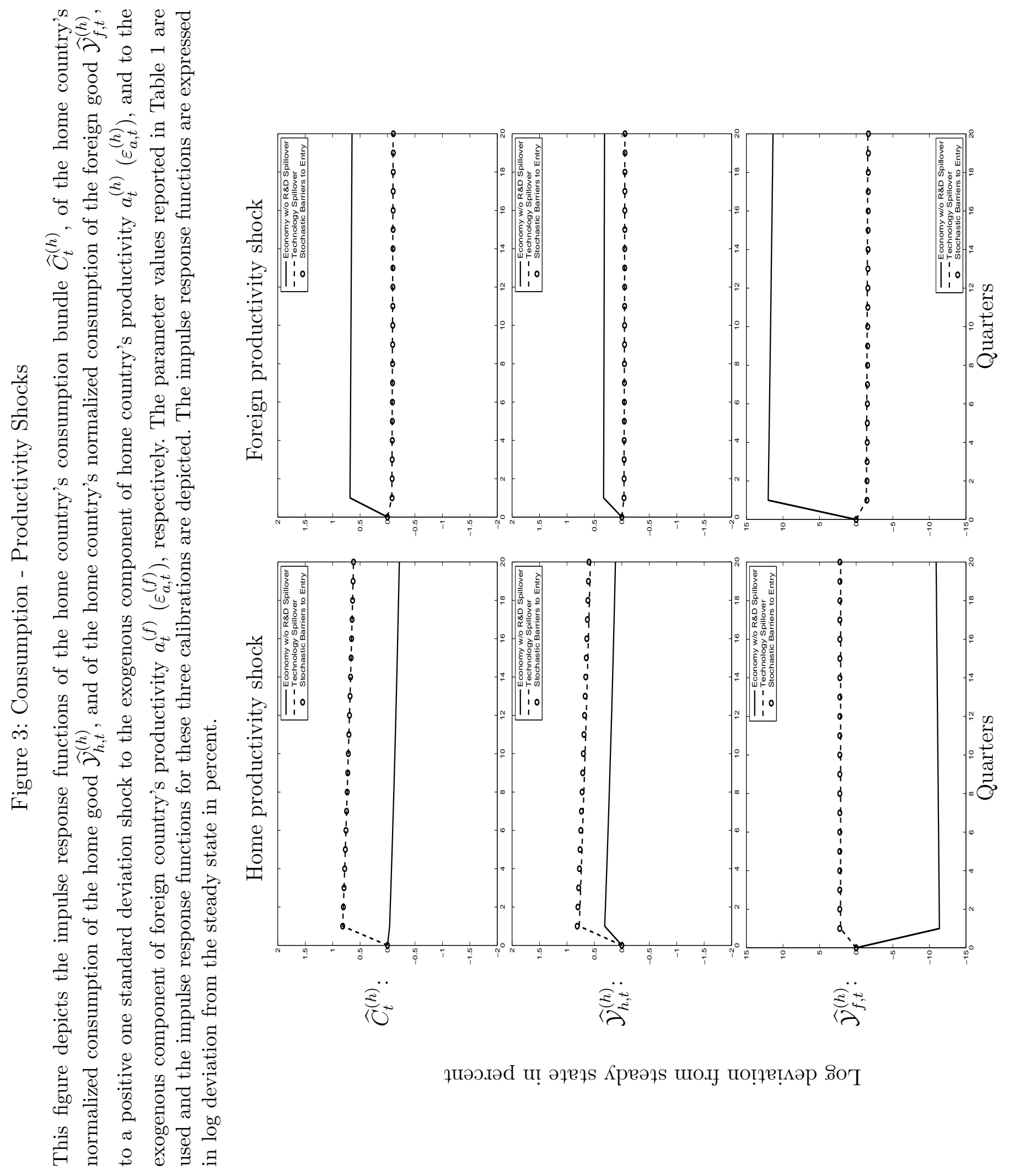




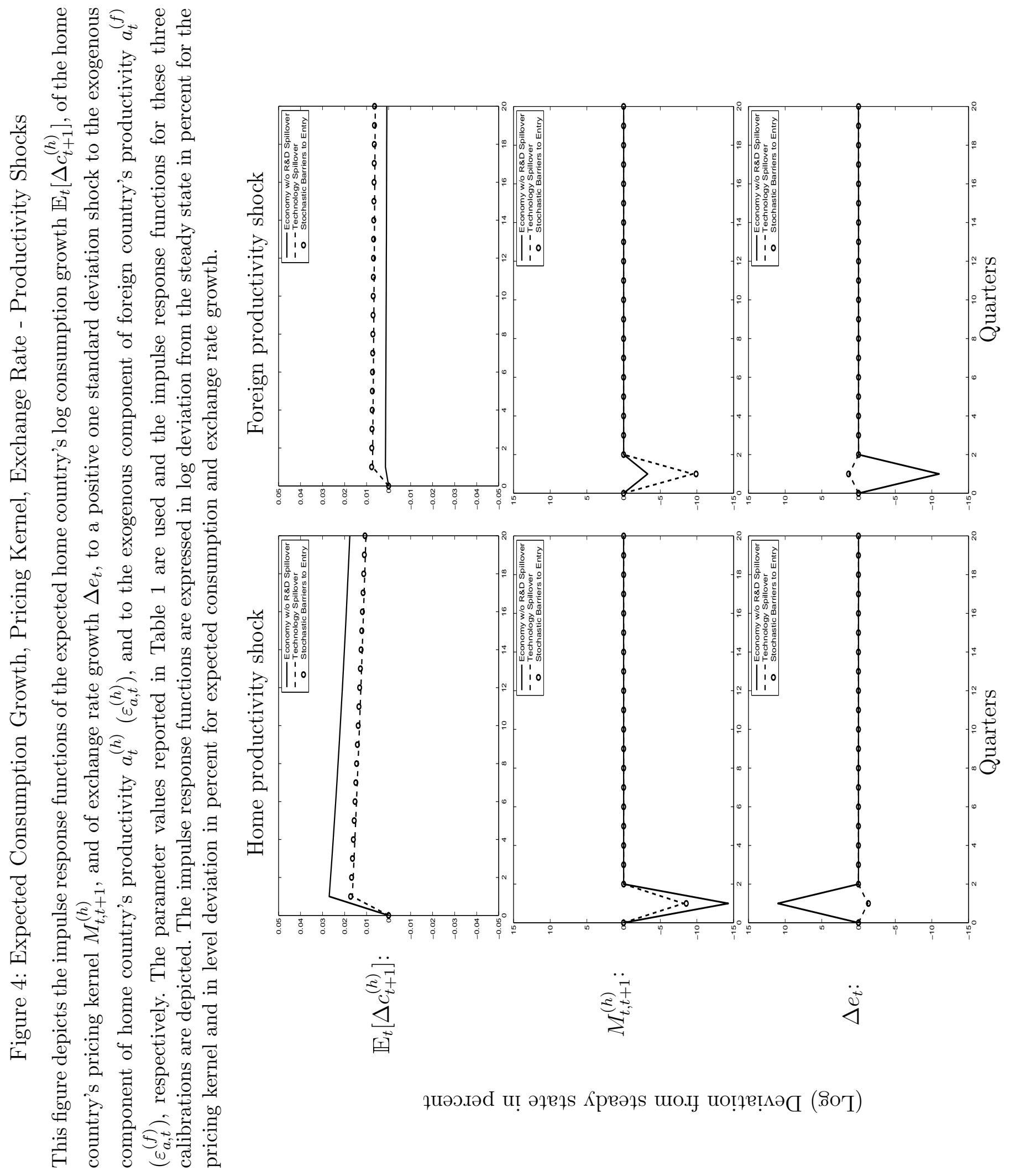




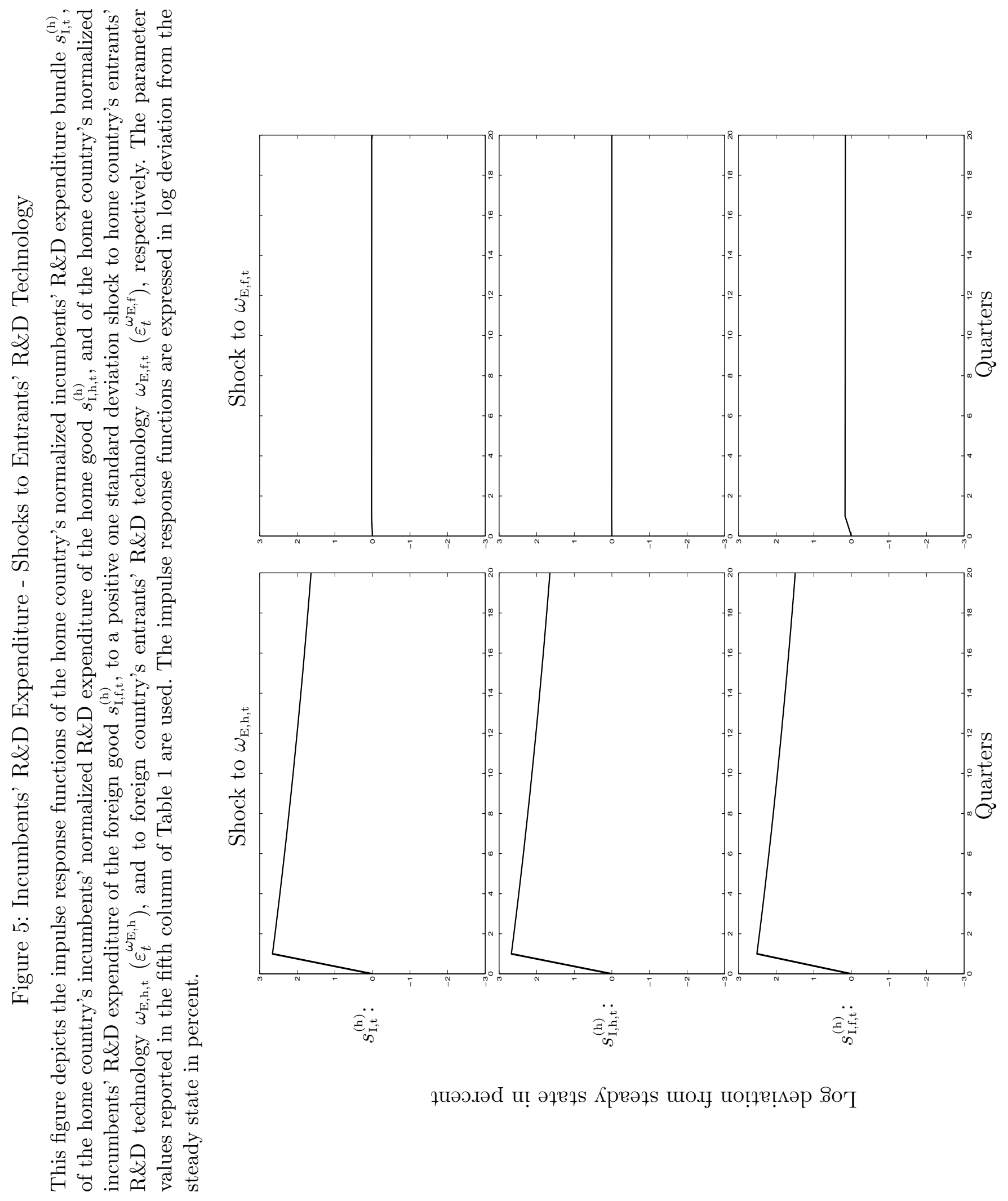




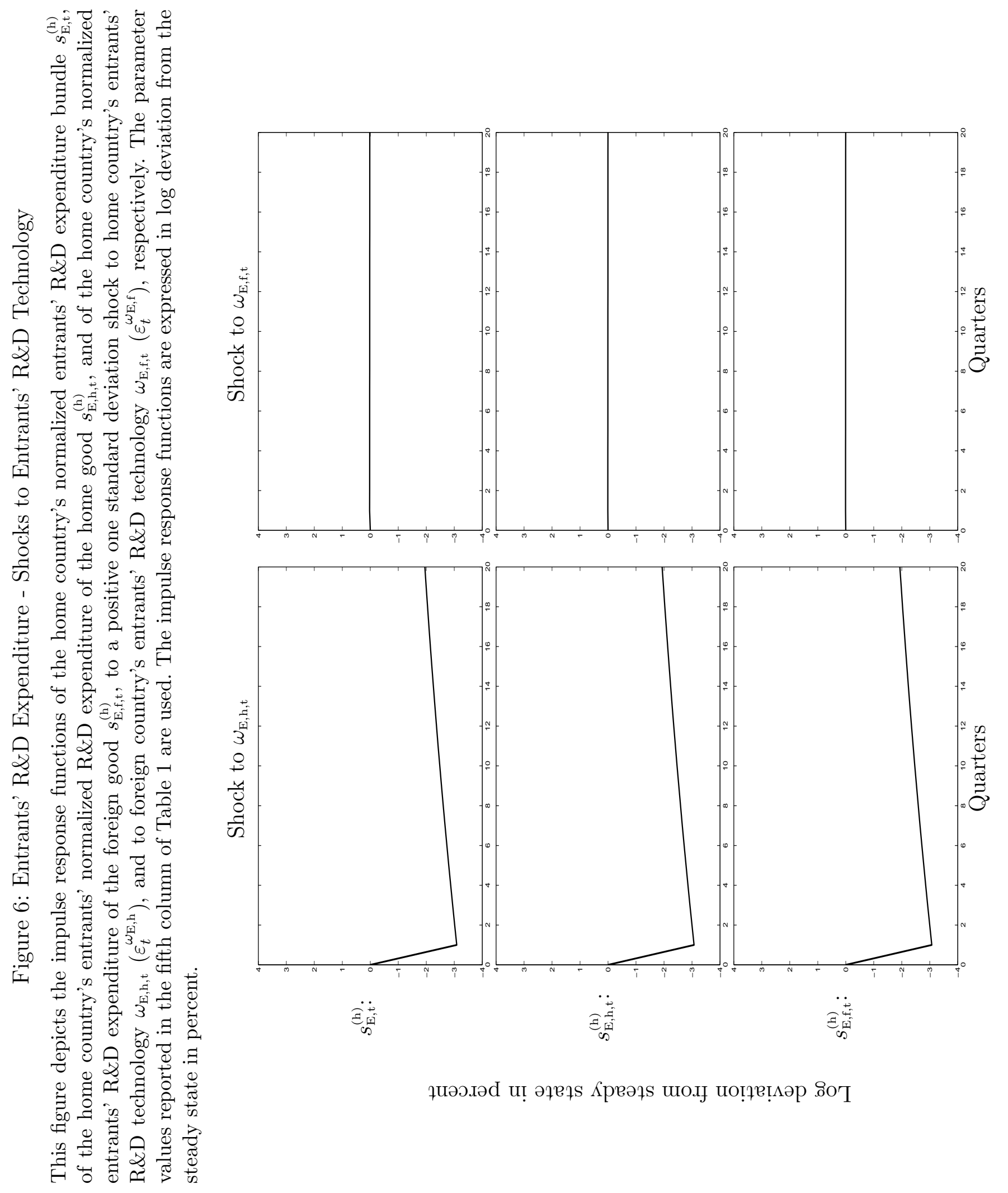




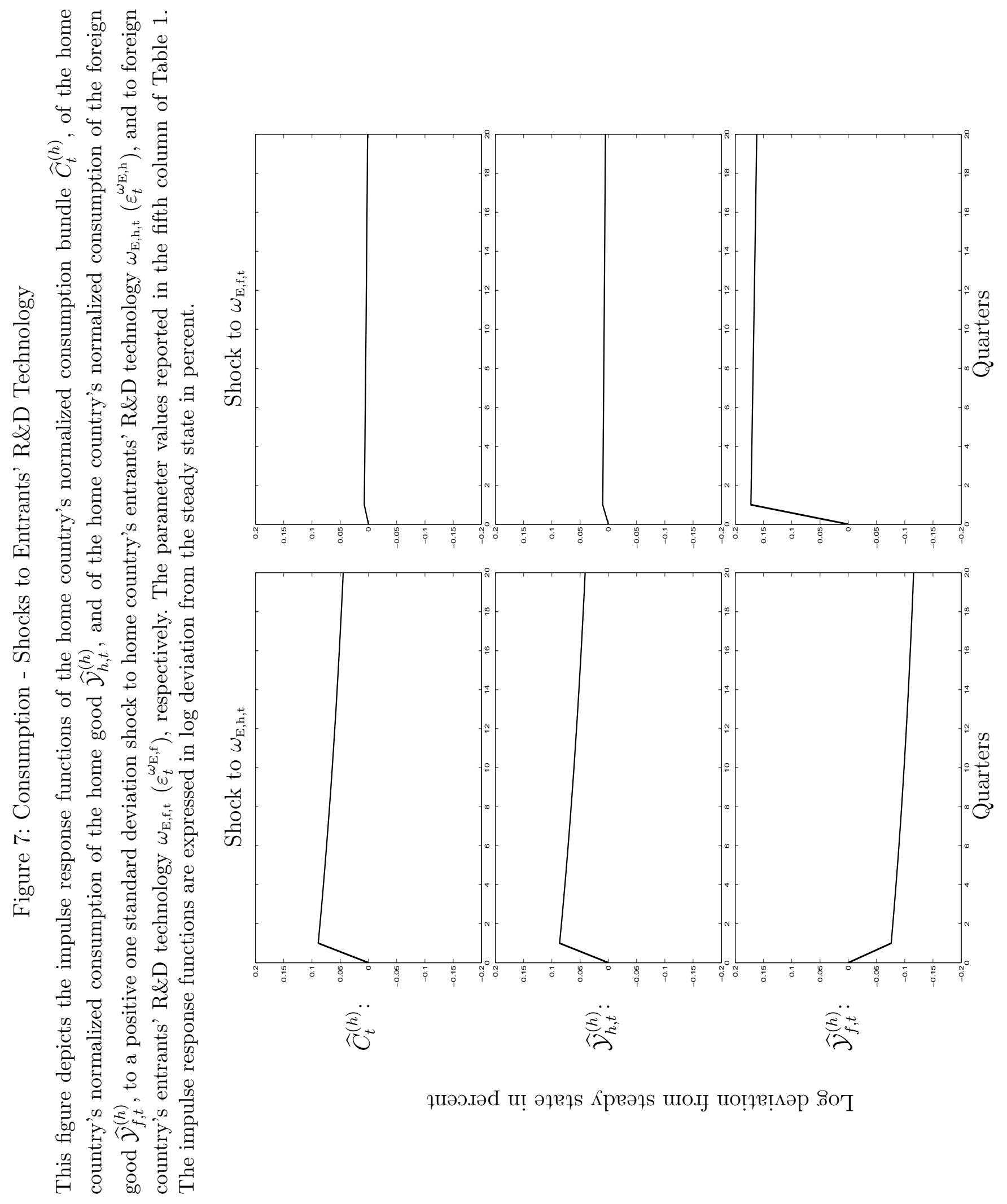




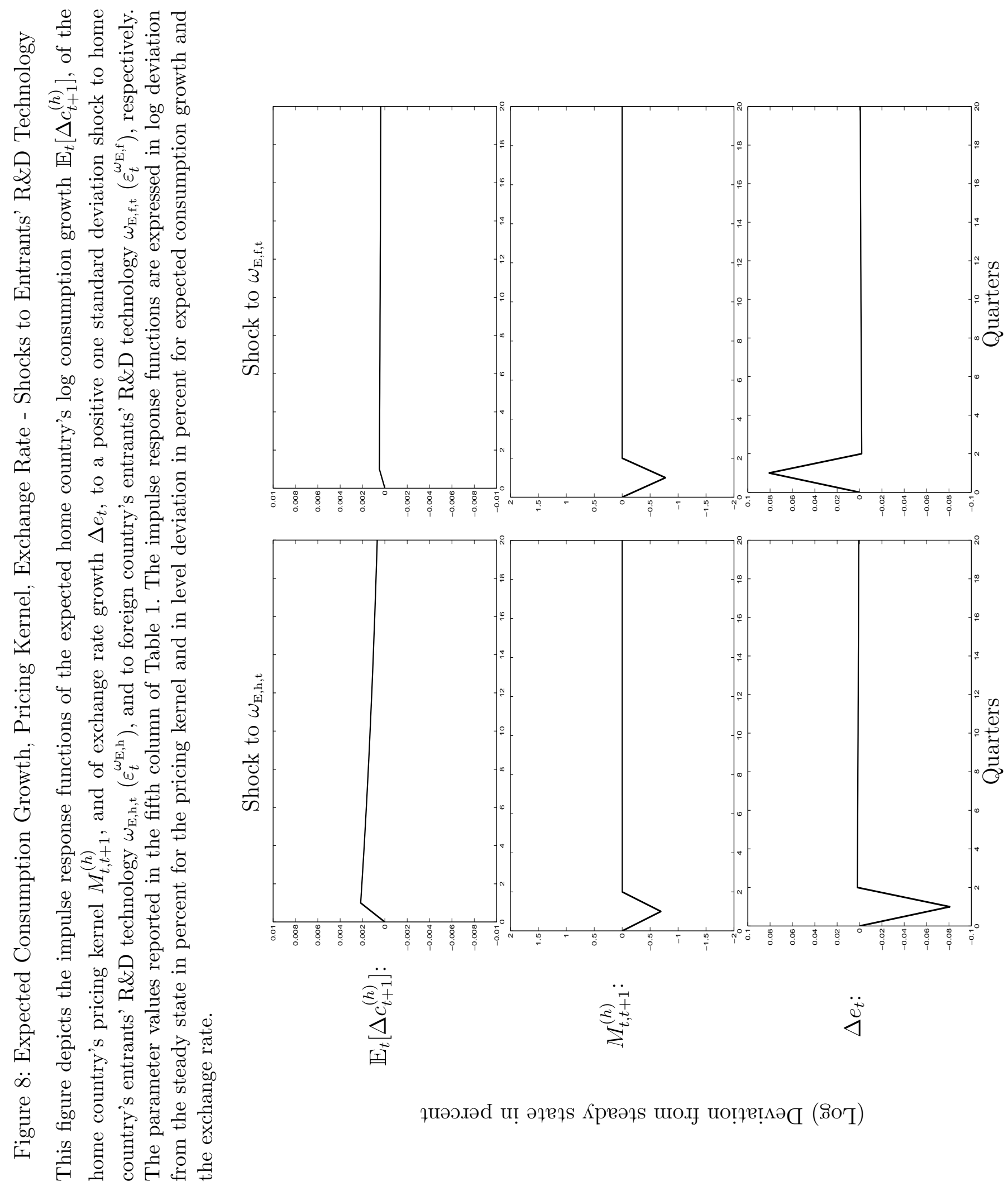




\section{A Derivations and Equilibrium}

\section{A.1 Solving Households' Consumption Allocation Problem}

There is a complete set of Arrow-Debreu securities (i.e. one-period-ahead claims to state-contingent final goods) available to households in both countries. These claims are denoted by $Q_{t+1}\left(\chi_{t+1}\right)$ where $\chi_{t+1}$ is the state of the economy at time $t+1$. If a household holds one unit of $Q_{t+1}\left(\chi_{t+1}\right)$ between time $t$ and $t+1$, it receives one unit of the home country's final good if the economy is in state $\chi_{t+1}$ at time $t+1$ and zero otherwise. Country $k$ 's household's holdings of these assets from time $t$ to time $t+1$ are given by $A_{t+1}^{(k)}\left(\chi_{t+1}\right) . P_{t}^{(h)}$ denotes the terms of trade or, equivalently, the price of the foreign final good in home final good units. Moreover, final good trading and financial markets are assumed to be frictionless.

Therefore, the home country's consumption household's allocation problem is

$$
\max _{\left\{\mathcal{Y}_{h, t}^{(h)}, \mathcal{Y}_{f, t}^{(h)}, A_{t+1}^{(h)}\left(\chi_{t+1}\right)\right\}}\left\{\left\{\left(1-\beta_{h}\right)\left(C_{t}^{(h)}\right)^{\frac{1-\gamma_{h}}{\theta_{h}}}+\beta_{h}\left(\mathbb{E}_{t}\left[\left(U_{t+1}^{(h)}\right)^{1-\gamma_{h}}\right]\right)^{\frac{1}{\theta_{h}}}\right\}^{\frac{1-\theta_{h}}{1-\gamma_{h}}}\right\},
$$

subject to the budget constraint

$$
\mathcal{Y}_{h, t}^{(h)}+P_{t}^{(h)} \mathcal{Y}_{f, t}^{(h)}+\int_{\chi_{t+1}} A_{t+1}^{(h)}\left(\chi_{t+1}\right) Q_{t+1}\left(\chi_{t+1}\right)=A_{t}^{(h)}+\mathcal{Y}_{t}^{(h)}
$$

where

$$
C_{t}^{(h)}=\left(\mathcal{Y}_{h, t}^{(h)}\right)^{\phi_{\mathrm{C}, \mathrm{h}}}\left(\mathcal{Y}_{f, t}^{(h)}\right)^{1-\phi_{\mathrm{C}, \mathrm{h}}} .
$$

Attaching the Lagrange-multiplier $\mu_{t}^{(h)}$ to the budget constraint, the first order conditions of this optimization problem are given by

$$
\begin{gathered}
\mu_{t}^{(h)}=\left(U_{t}^{(h)}\right)^{1-\frac{1-\gamma_{h}}{\theta_{h}}}\left(1-\beta_{h}\right)\left(C_{t}^{(h)}\right)^{-\frac{1}{\psi_{h}}} \phi_{\mathrm{C}, \mathrm{h}} \frac{C_{t}^{(h)}}{\mathcal{Y}_{h, t}^{(h)}} \\
P_{t}^{(h)} \mu_{t}^{(h)}=\left(U_{t}^{(h)}\right)^{1-\frac{1-\gamma_{h}}{\theta_{h}}}\left(1-\beta_{h}\right)\left(C_{t}^{(h)}\right)^{-\frac{1}{\psi_{h}}}\left(1-\phi_{\mathrm{C}, \mathrm{h}}\right) \frac{C_{t}^{(h)}}{\mathcal{Y}_{f, t}^{(h)}} \\
Q_{t+1}\left(\chi_{t+1}\right) \mu_{t}^{(h)}=\beta_{h}\left(U_{t}^{(h)}\right)^{1-\frac{1-\gamma_{h}}{\theta_{h}}}\left(\mathbb{E}_{t}\left[\left(U_{t+1}^{(h)}\right)^{1-\gamma_{h}}\right]\right)^{\frac{1}{\theta_{h}}-1} \mathbb{E}_{t}\left[\left(U_{t+1}^{(h)}\right)^{-\gamma_{h}} \frac{\partial U_{t+1}^{(h)}}{\partial A_{t+1}^{(h)}\left(\chi_{t+1}\right)}\right] .
\end{gathered}
$$

Using the envelope theorem, I obtain $\frac{\partial U_{t+1}^{(h)}}{\partial A_{t+1}^{(h)}\left(\chi_{t+1}\right)}=\mu_{t+1}^{(h)}$. Moreover, by noting that the last first order condition determining the Arrow-Debreu price $Q_{t+1}$ holds for each state $\chi_{t+1}$, one obtains by combining all first conditions and, for the ease of exposition, by not explicitly writing the dependence on the state $\chi_{t+1}$

$$
\begin{aligned}
P_{t}^{(h)} \phi_{\mathrm{C}, \mathrm{h}} \mathcal{Y}_{f, t}^{(h)} & =\left(1-\phi_{\mathrm{C}, \mathrm{h}}\right) \mathcal{Y}_{h, t}^{(h)} \\
Q_{t+1} & =M_{t, t+1}^{(h)} \frac{C_{t+1}^{(h)}}{C_{t}^{(h)}} \frac{\mathcal{Y}_{h, t}^{(h)}}{\mathcal{Y}_{h, t+1}^{(h)}}
\end{aligned}
$$


Similarly, the foreign country's household's consumption allocation problem is

$$
\max _{\left\{\mathcal{Y}_{f, t}^{(f)}, \mathcal{Y}_{h, t}^{(f)}, A_{t+1}^{(f)}\left(\chi_{t+1}\right)\right\}}\left\{\left\{\left(1-\beta_{f}\right)\left(C_{t}^{(f)}\right)^{\frac{1-\gamma_{f}}{\theta_{f}}}+\beta_{f}\left(\mathbb{E}_{t}\left[\left(U_{t+1}^{(f)}\right)^{1-\gamma_{f}}\right]\right)^{\frac{1}{\theta_{f}}}\right\}^{\frac{1-\theta_{f}}{1-\gamma_{f}}}\right\},
$$

subject to the budget constraint (written in units of the home country's final good)

$$
P_{t}^{(h)} \mathcal{Y}_{f, t}^{(f)}+\mathcal{Y}_{h, t}^{(f)}+\int_{\chi_{t+1}} A_{t+1}^{(f)}\left(\chi_{t+1}\right) Q_{t+1}\left(\chi_{t+1}\right)=A_{t}^{(f)}+P_{t}^{(h)} \mathcal{Y}_{t}^{(f)},
$$

where

$$
C_{t}^{(f)}=\left(\mathcal{Y}_{f, t}^{(f)}\right)^{\phi_{\mathrm{C}, \mathrm{f}}}\left(\mathcal{Y}_{h, t}^{(f)}\right)^{1-\phi_{\mathrm{C}, \mathrm{f}}}
$$

Attaching the Lagrange-multiplier $\mu_{t}^{(f)}$ to the budget constraint, the first order conditions of this optimization problem are given by

$$
\begin{aligned}
P_{t}^{(h)} \mu_{t}^{(f)} & =\left(U_{t}^{(f)}\right)^{1-\frac{1-\gamma_{f}}{\theta_{f}}}\left(1-\beta_{f}\right)\left(C_{t}^{(f)}\right)^{-\frac{1}{\psi_{f}}} \phi_{\mathrm{C}, \mathrm{f}} \frac{C_{t}^{(f)}}{\mathcal{Y}_{f, t}^{(f)}} \\
\mu_{t}^{(f)} & =\left(U_{t}^{(f)}\right)^{1-\frac{1-\gamma_{f}}{\theta_{f}}}\left(1-\beta_{f}\right)\left(C_{t}^{(f)}\right)^{-\frac{1}{\psi_{f}}}\left(1-\phi_{\mathrm{C}, \mathrm{f}}\right) \frac{C_{t}^{(f)}}{\mathcal{Y}_{h, t}^{(f)}} \\
Q_{t+1}\left(\chi_{t+1}\right) \mu_{t}^{(f)} & =\beta_{f}\left(U_{t}^{(f)}\right)^{1-\frac{1-\gamma_{f}}{\theta_{f}}}\left(\mathbb{E}_{t}\left[\left(U_{t+1}^{(f)}\right)^{1-\gamma_{f}}\right]\right)^{\frac{1}{\theta_{f}}-1} \mathbb{E}_{t}\left[\left(U_{t+1}^{(f)}\right)^{-\gamma_{f}} \frac{\partial U_{t+1}^{(f)}}{\partial A_{t+1}^{(f)}\left(\chi_{t+1}\right)}\right] .
\end{aligned}
$$

Using again the envelope theorem implies $\frac{\partial U_{t+1}^{(f)}}{\partial A_{t+1}^{(f)}\left(\chi_{t+1}\right)}=\mu_{t+1}^{(f)}$. With this and the same notational conventions as used for the home country's problem, I obtain

$$
\begin{aligned}
\phi_{\mathrm{C}, \mathrm{f}} \mathcal{Y}_{h, t}^{(f)} & =P_{t}^{(h)}\left(1-\phi_{\mathrm{C}, \mathrm{f}}\right) \mathcal{Y}_{f, t}^{(f)} \\
Q_{t+1} & =M_{t, t+1}^{(f)} \frac{C_{t+1}^{(f)}}{C_{t}^{(f)}} \frac{\mathcal{Y}_{f, t}^{(f)}}{\mathcal{Y}_{f, t+1}^{(f)}} \frac{P_{t}^{(h)}}{P_{t+1}^{(h)}} .
\end{aligned}
$$

In equilibrium, the market for Arrow-Debreu securities clears, i.e. $A_{t}^{(h)}+A_{t}^{(f)}=0$ at each time $t \geq 0$. Moreover, the final good markets in both countries have to clear, i.e. for each time $t$ the following restrictions apply

$$
\begin{aligned}
& \mathcal{Y}_{t}^{(h)}=\mathcal{Y}_{h, t}^{(h)}+\mathcal{Y}_{h, t}^{(f)} \\
& \mathcal{Y}_{t}^{(f)}=\mathcal{Y}_{f, t}^{(f)}+\mathcal{Y}_{f, t}^{(h)} .
\end{aligned}
$$

Finally, equating conditions (A3) and (A6) and defining the "pseudo" Pareto share $S_{t}=\frac{1}{P_{t}^{(h)}} \frac{\mathcal{Y}_{h, t}^{(h)}}{\mathcal{Y}_{f, t}^{(f)}}$ implies the recursion

$$
S_{t}=S_{t-1} \frac{M_{t-1, t}^{(h)}}{M_{t-1, t}^{(f)}} \frac{C_{t}^{(h)} / C_{t-1}^{(h)}}{C_{t}^{(f)} / C_{t-1}^{(f)}}
$$


Rewriting equations (A2) and (A5) using this "pseudo" Pareto share gives

$$
\begin{aligned}
S_{t} \phi_{\mathrm{C}, \mathrm{f}} \mathcal{Y}_{h, t}^{(f)} & =\left(1-\phi_{\mathrm{C}, \mathrm{f}}\right) \mathcal{Y}_{h, t}^{(h)} \\
S_{t}\left(1-\phi_{\mathrm{C}, \mathrm{h}}\right) \mathcal{Y}_{f, t}^{(f)} & =\phi_{\mathrm{C}, \mathrm{h}} \mathcal{Y}_{f, t}^{(h)} .
\end{aligned}
$$

These two conditions jointly with the market clearing conditions (A7) and (A8) determine the allocation of the two final goods for consumption in each country given the recursion for the "pseudo" Pareto share (A9).

\section{A.2 Equilibrium of the Final and Intermediate Good Sectors}

The first order conditions of the final good firm's problem

$$
\max _{\left\{I_{t}^{(k)}, K_{t+1}^{(k)}, L_{t}^{(k)}, x_{i_{k}, \mathrm{t}}^{(\mathrm{k})}\right\}_{i_{k} \in[0,1] ; t \geq 0}} \mathbb{E}_{0}\left[\sum_{t=0}^{\infty} \mathbf{M}_{t}^{(k), l o c}\left(Y_{t}^{(k)}-I_{t}^{(k)}-\omega_{t}^{(k)} L_{t}^{(k)}-\int_{0}^{1} p_{i_{k}, \mathrm{t}}^{(\mathrm{k})}\left(q_{i_{k}, \mathrm{t}}^{(\mathrm{k})}\right) x_{i_{k}, \mathrm{t}}^{(\mathrm{k})} d i_{k}\right)\right]
$$

subject to

$$
K_{t+1}^{(k)}=\left(1-\delta_{k}\right) K_{t}^{(k)}+\Lambda^{(k)}\left(\frac{I_{t}^{(k)}}{K_{t}^{(k)}}\right) K_{t}^{(k)}
$$

imply

$$
\begin{aligned}
w_{t}^{(k)} & =\left(1-\alpha_{k}\right)\left(1-\xi_{k}\right) Y_{t}^{(k)} \\
1 & =\mathbb{E}_{t}\left[\mathbb{M}_{t, t+1}^{(k), l o c}\left(\Lambda_{t}^{(k)}\right)^{\prime}\left(\frac{\alpha_{k}\left(1-\xi_{k}\right) Y_{t+1}^{(k)}-I_{t+1}^{(k)}}{K_{t+1}^{(k)}}+\frac{\Lambda_{t+1}^{(k)}+1-\delta_{k}}{\left(\Lambda_{t+1}^{(k)}\right)^{\prime}}\right)\right] \\
p_{i_{k}, \mathrm{t}}^{(\mathrm{k})} & =\left[\left(K_{t}^{(k)}\right)^{\alpha_{k}}\left(\Omega_{t}^{(k)} L_{t}^{(k)}\right)^{1-\alpha_{k}}\right]^{1-\xi_{k}} \xi_{k}\left(G_{t}^{(k)}\right)^{\xi_{k}-\frac{1}{\nu_{k}}}\left(q_{i_{k}, \mathrm{t}}^{(\mathrm{k})}\right)^{1-\frac{1}{\nu_{k}}}\left(x_{i_{k}, \mathrm{t}}^{(\mathrm{k})}\right)^{\frac{1}{\nu_{k}}-1},
\end{aligned}
$$

where $\Lambda_{t}^{(k)} \equiv \Lambda^{(k)}\left(\frac{I_{t}^{(k)}}{K_{t}^{(k)}}\right),\left(\Lambda^{(k)}\right)_{t}^{\prime} \equiv\left(\Lambda^{(k)}\right)^{\prime}\left(\frac{I_{t}^{(k)}}{K_{t}^{(k)}}\right)$.

From the final good firm's first order condition $(A 14)$, the final good firm's demand for intermediate good $i_{k}, x_{i_{k}, \mathrm{t}}^{(\mathrm{k})}$, is given by

$$
x_{i_{k}, \mathrm{t}}^{(\mathrm{k})}=\left(\xi_{k}\right)^{\frac{\nu_{k}}{\nu_{k}-1}}\left(\left(K_{t}^{(k)}\right)^{\alpha_{k}}\left(\Omega_{t}^{(k)} L_{t}^{(k)}\right)^{1-\alpha_{k}}\right)^{\frac{\left(1-\xi_{k}\right) \nu_{k}}{\nu_{k}-1}}\left(G_{t}^{(k)}\right)^{\frac{\xi_{k} \nu_{k}-1}{\nu_{k}-1}}\left(p_{i_{k}, \mathrm{t}}^{(\mathrm{k})}\right)^{\frac{\nu_{k}}{1-\nu_{k}}} q_{i_{k}, \mathrm{t}}^{(\mathrm{k})}
$$

Using (A15) in the incumbent's problem (9) leads to the following price and profit

$$
p_{i_{k}, \mathrm{t}}^{(\mathrm{k})}=\nu_{k} \mu_{k}, \quad \pi_{i_{k}, \mathrm{t}}^{(\mathrm{k})}=\left(\nu_{k}-1\right) \mu_{k} x_{i_{k}, \mathrm{t}}^{(\mathrm{k})} .
$$

Hence, the monopoly price is $\nu_{k}$ multiplied by marginal costs $\mu_{k}$. Thus, the parameter $\nu_{k}$ has two properties. First, it measures the monopoly markup or market power of incumbents. Second, it determines the elasticity of substitution between any two intermediate goods given by $\frac{\nu_{k}}{\nu_{k}-1}$. Substituting $(A 15)$ and (A16) into (6) yields the following expression for the composite of intermediate goods

$$
G_{t}^{(k)}=\left(\frac{\xi_{k}}{\nu_{k} \mu_{k}}\right)^{\frac{1}{1-\xi_{k}}}\left(K_{t}^{(k)}\right)^{\alpha_{k}}\left(\Omega_{t}^{(k)} L_{t}^{(k)}\right)^{1-\alpha_{k}}\left(Q_{t}^{(k)}\right)^{\frac{\nu_{k}-1}{1-\xi_{k}}}
$$

Using again $(A 16)$ and $(A 17)$, I can rewrite the demand for intermediate good $i_{k}$ in country $k, x_{i_{k}, \mathrm{t}}^{(\mathrm{k})}$, as 
a linear function of quality which substantially facilitates aggregation

$$
x_{i_{k}, \mathrm{t}}^{(\mathrm{k})}=\left(\frac{\xi_{k}}{\mu_{k} \nu_{k}}\right)^{\frac{1}{1-\xi_{k}}}\left(K_{t}^{(k)}\right)^{\alpha_{k}}\left(\Omega_{t}^{(k)} L_{t}^{(k)}\right)^{1-\alpha_{k}}\left(Q_{t}^{(k)}\right)^{\frac{\xi_{k} \nu_{k}-1}{1-\xi_{k}}} q_{i_{k}, \mathrm{t}}^{(\mathrm{k})} .
$$

Linearity in intermediate good demand translates into the following aggregate quantities by using (3), $(A 16),(A 17)$ and $(A 18)$

$$
\begin{aligned}
X_{t}^{(k)} & =\int_{0}^{1} x_{i_{k}, \mathrm{t}}^{(\mathrm{k})} d i_{k}=\left(\frac{\xi_{k}}{\mu_{k} \nu_{k}}\right)^{\frac{1}{1-\xi_{k}}}\left(K_{t}^{(k)}\right)^{\alpha_{k}}\left(\Omega_{t}^{(k)} L_{t}^{(k)}\right)^{1-\alpha_{k}}\left(Q_{t}^{(k)}\right)^{\frac{\xi_{k}\left(\nu_{k}-1\right)}{1-\xi_{k}}} \\
\Pi_{t}^{(k)} & =\int_{0}^{1} \pi_{i_{k}, \mathrm{t}}^{(\mathrm{k})} d i_{k}=\left(\nu_{k}-1\right) \mu_{k} X_{t}^{(k)} \\
Y_{t}^{(k)} & =\left(\frac{\xi_{k}}{\mu_{k} \nu_{k}}\right)^{\frac{\xi_{k}}{1-\xi_{k}}}\left(K_{t}^{(k)}\right)^{\alpha_{k}}\left(\Omega_{t}^{(k)} L_{t}^{(k)}\right)^{1-\alpha_{k}}\left(Q_{t}^{(k)}\right)^{\frac{\xi_{k}\left(\nu_{k}-1\right)}{1-\xi_{k}}} .
\end{aligned}
$$

To ensure balanced growth, I need to impose a restriction on the exponent of technology capital $Q_{t}^{(k)}$ in each country and thus I assume

$$
\frac{\left(\nu_{k}-1\right) \xi_{k}}{1-\xi_{k}}=1-\alpha_{k}, \quad k=h, f .
$$

This condition implies the following functional forms for final good output and the demand for intermediate goods

$$
\begin{aligned}
Y_{t}^{(k)} & =\left(\frac{\xi_{k}}{\mu_{k} \nu_{k}}\right)^{\frac{\xi_{k}}{1-\xi_{k}}}\left(K_{t}^{(k)}\right)^{\alpha_{k}}\left(\Omega_{t}^{(k)} Q_{t}^{(k)} L_{t}^{(k)}\right)^{1-\alpha_{k}} \\
X_{t}^{(k)} & =\frac{\xi_{k}}{\nu_{k} \mu_{k}} Y_{t}^{(k)} .
\end{aligned}
$$

Technology capital $Q_{t}^{(k)}$ thus acts as an endogenous "labor augmenting" productivity factor. It determines total factor productivity (TFP) alongside exogenous shocks. Furthermore, it measures the size of the economy in country $k$ as it determines the endogenously growing part of TFP. The exogenous shocks have zero mean and thus do not induce growth in the economy. Nevertheless, the productivity shocks $\varepsilon_{z, t}, \varepsilon_{a, t}^{(h)}$, and $\varepsilon_{a, t}^{(f)}$ are essential to make productivity growth stochastic. Technological capital can be proxied in the data by the number of patents and the number of citations for a given patent. The latter measure especially determines the "quality" (impact) of a patent.

\section{A.3 R\&D Decisions by Incumbents and Entrants}

\section{A.3.1 Incumbents}

The value of each incumbents is determined by the Bellman equation

$$
\begin{aligned}
v_{t}^{(k)}= & \max _{\left\{\begin{array}{c}
(\mathrm{k}) \\
s_{\mathrm{I}, \mathrm{k}, \mathrm{t}}, s_{\mathrm{I},-\mathrm{k}, \mathrm{t}}^{(\mathrm{k})}
\end{array}\right.}\left\{\pi_{t}^{(k)}-s_{\mathrm{I}, \mathrm{k}, \mathrm{t}}^{(\mathrm{k})}-P_{t}^{(k)} s_{\mathrm{I},-\mathrm{k}, \mathrm{t}}^{(\mathrm{k})}\right. \\
& \left.+\mathbb{E}_{t}\left[\mathbb{M}_{t, t+1}^{(k), l o c} v_{t+1}^{(k)}\left(\Phi_{\mathrm{I}}^{(\mathrm{k})}\left(s_{\mathrm{I}, \mathrm{t}}^{(\mathrm{k})}\right) \kappa_{\mathrm{I}, \mathrm{k}}+\left(1-\Phi_{\mathrm{I}}^{(\mathrm{k})}\left(s_{\mathrm{I}, \mathrm{t}}^{(\mathrm{k})}\right)-\hat{\Phi}_{\mathrm{E}, \mathrm{t}}^{(\mathrm{k})}\left(s_{\mathrm{E}, \mathrm{t}}^{(\mathrm{k})}\right)\right) \kappa_{\mathrm{D}, \mathrm{k}}\right)\right]\right\} .
\end{aligned}
$$


The net profit $\pi_{t}^{(k)}-s_{\mathrm{I}, \mathrm{k}, \mathrm{t}}^{(\mathrm{k})}-P_{t}^{(k)} s_{\mathrm{I},-\mathrm{k}, \mathrm{t}}^{(\mathrm{k})}$ can thus be thought of as the dividends distributed by the incumbent. This is equivalent to incumbent's value $v_{t+1}^{(k)}$ evolving as a random variable with the following distribution

$$
v_{t+1}^{(k)}=\left\{\begin{array}{lcc}
0 & \text { with probability } & \hat{\Phi}_{\mathrm{E}, \mathrm{t}}^{(\mathrm{k})}\left(s_{\mathrm{E}, \mathrm{t}}^{(\mathrm{k})}\right) \\
\kappa_{\mathrm{I}, \mathrm{k}} v_{t}^{(k)} & \text { with probability } & \Phi_{\mathrm{I}}^{(\mathrm{k})}\left(s_{\mathrm{I}, \mathrm{t}}^{(\mathrm{k})}\right) \\
\kappa_{\mathrm{D}, \mathrm{k}} v_{t}^{(k)} & \text { otherwise. } &
\end{array}\right.
$$

The first order conditions of the Bellman equation $(A 20)$ with respect to incumbents' $\mathrm{R} \& \mathrm{D}$ expenditure of the home and foreign consumption good imply

$$
\begin{aligned}
1 & =\left(\Phi_{\mathrm{I}}^{(\mathrm{k})}\right)^{\prime}\left(s_{\mathrm{I}, \mathrm{t}}^{(\mathrm{k})}\right) \phi_{\mathrm{I}, \mathrm{k}} \frac{s_{\mathrm{I}, \mathrm{t}}^{(\mathrm{k})}}{s_{\mathrm{I}, \mathrm{k}, \mathrm{t}}^{(\mathrm{k})}}\left(\kappa_{\mathrm{I}, \mathrm{k}}-\kappa_{\mathrm{D}, \mathrm{k}}\right) \mathbb{E}_{t}\left[\mathbb{M}_{t, t+1}^{(k), l o c} v_{t+1}^{(k)}\right] \\
P_{t}^{(k)} & =\left(\Phi_{\mathrm{I}}^{(\mathrm{k})}\right)^{\prime}\left(s_{\mathrm{I}, \mathrm{t}}^{(\mathrm{k})}\right)\left(1-\phi_{\mathrm{I}, \mathrm{k}}\right) \frac{s_{\mathrm{I}, \mathrm{t}}^{(\mathrm{k})}}{s_{\mathrm{I},-\mathrm{k}, \mathrm{t}}^{(\mathrm{k})}}\left(\kappa_{\mathrm{I}, \mathrm{k}}-\kappa_{\mathrm{D}, \mathrm{k}}\right) \mathbb{E}_{t}\left[\mathbb{M}_{t, t+1}^{(k), l o c} v_{t+1}^{(k)}\right],
\end{aligned}
$$

where $\left(\Phi_{\mathrm{I}}^{(\mathrm{k})}\right)^{\prime}\left(s_{\mathrm{I}, \mathrm{t}}^{(\mathrm{k})}\right)=\eta_{\mathrm{I}, \mathrm{k}} \omega_{\mathrm{I}, \mathrm{k}}\left(s_{\mathrm{I}, \mathrm{t}}^{(\mathrm{k})}\right)^{\omega_{\mathrm{I}, \mathrm{k}}-1}$

\section{A.3.2 Entrants}

Entrants maximize the net present value of future profits achieved if they become incumbents

$$
\max _{\left\{s_{\mathrm{E}, \mathrm{k}, \mathrm{t}}^{(\mathrm{k})}, s_{\mathrm{E},-\mathrm{k}, \mathrm{t}}^{(\mathrm{k})}\right\}}\left\{\hat{\Phi}_{\mathrm{E}, \mathrm{t}}^{(\mathrm{k})}\left(s_{\mathrm{E}, \mathrm{t}}^{(\mathrm{k})}\right) \kappa_{\mathrm{E}, \mathrm{k}} \mathbb{E}_{t}\left[\mathrm{M}_{t, t+1}^{(k), l o c} v_{t+1}^{(k)}\right]-s_{\mathrm{E}, \mathrm{k}, \mathrm{t}}^{(\mathrm{k})}-P_{t}^{(k)} s_{\mathrm{E},-\mathrm{k}, \mathrm{t}}^{(\mathrm{k})}\right\}
$$

Since potential entrants are atomistic, each potential entrant takes the component $\Phi_{\mathrm{E}, \mathrm{t}}^{(\mathrm{k})}\left(s_{\mathrm{E}, \mathrm{t}}^{(\mathrm{k})}\right)$ in $\hat{\Phi}_{\mathrm{E}, \mathrm{t}}^{(\mathrm{k})}\left(s_{\mathrm{E}, \mathrm{t}}^{(\mathrm{k})}\right) \equiv$ $s_{\mathrm{E}, \mathrm{t}}^{(\mathrm{k})} \Phi_{\mathrm{E}, \mathrm{t}}^{(\mathrm{k})}\left(s_{\mathrm{E}, \mathrm{t}}^{(\mathrm{k})}\right)$ as given. This assumption represents a congestion externality and captures the fact that all potential entrants in the intermediate good $i_{k}$ product line are likely to try similar ideas. Under this assumption, the first order conditions lead to the following two free entry conditions for potential entrants determining their optimal R\&D expenditure of the home and foreign consumption good

$$
\begin{aligned}
1 & =\Phi_{\mathrm{E}, \mathrm{t}}^{(\mathrm{k})}\left(s_{\mathrm{E}, \mathrm{t}}^{(\mathrm{k})}\right) \phi_{\mathrm{E}, \mathrm{k}} \frac{s_{\mathrm{E}, \mathrm{t}}^{(\mathrm{k})}}{s_{\mathrm{E}, \mathrm{k}, \mathrm{t}}^{(\mathrm{t})}} \kappa_{\mathrm{E}, \mathrm{k}} \mathbb{E}_{t}\left[\mathrm{M}_{t, t+1}^{(k), l o c} v_{t+1}^{(k)}\right] \\
P_{t}^{(k)} & =\Phi_{\mathrm{E}, \mathrm{t}}^{(\mathrm{k})}\left(s_{\mathrm{E}, \mathrm{t}}^{(\mathrm{k})}\right)\left(1-\phi_{\mathrm{E}, \mathrm{k}}\right) \frac{s_{\mathrm{E}, \mathrm{t}}^{(\mathrm{k})}}{s_{\mathrm{E},-\mathrm{k}, \mathrm{t}}^{(\mathrm{k})}} \kappa_{\mathrm{E}, \mathrm{k}} \mathbb{E}_{t}\left[\mathbb{M}_{t, t+1}^{(k), l o c} v_{t+1}^{(k)}\right] .
\end{aligned}
$$

R\&D expenditures of incumbents and potential entrants are thus chosen such that the marginal benefits of $\mathrm{R} \& \mathrm{D}$ are equal to the marginal costs.

\section{A.4 Definition of Equilibrium}

The decentralized equilibrium allocation in this economy consists of (i) time paths of the net output available for consumption and the allocation of final goods $\left\{\mathcal{Y}_{t}^{(k)}, \mathcal{Y}_{f, t}^{(k)}, \mathcal{Y}_{h, t}^{(k)}\right\}_{k \in\{h, f\}, t=0}^{t=\infty}$; (ii) time paths of consumption levels, physical capital, and investment $\left\{C_{t}^{(k)}, K_{t}^{(k)}, I_{t}^{(k)}\right\}_{k \in\{h, f\}, t=0}^{t=\infty}$; (iii) time paths of quality growth $\left\{Q_{t+1}^{(k)} / Q_{t}^{(k)}\right\}_{k \in\{h, f\}, t=0}^{t=\infty}$; (iv) time paths of incumbents' R\&D expenditures $\left\{s_{\mathrm{I}, i_{k}, \mathrm{t}}^{(\mathrm{k})}, s_{\mathrm{I}, \mathrm{k}, i_{k}, \mathrm{t}}^{(\mathrm{k})}, s_{\mathrm{I},-\mathrm{k}, i_{k}, \mathrm{t}}^{(\mathrm{k})}\right\}_{k \in\{h, f\}, i_{k} \in[0,1], t=0}^{t=\infty} ;(\mathrm{v})$ time paths of potential entrants' R\&D expenditures $\left\{s_{\mathrm{E}, i_{k}, \mathrm{t}}^{(\mathrm{k})}\right.$, 
$\left.s_{\mathrm{E}, \mathrm{k}, i_{k}, \mathrm{t}}^{(\mathrm{k})}, s_{\mathrm{E},-\mathrm{k}, i_{k}, \mathrm{t}}^{(\mathrm{k})}\right\}_{k \in\{h, f\}, i_{k} \in[0,1], t=0}^{t=\infty} ;(\mathrm{vi})$ time paths of prices and quantities for each intermediate good, and value functions of each incumbent $\left\{p_{i_{k}, \mathrm{t}}^{(\mathrm{k})}, x_{i_{k}, \mathrm{t}}^{(\mathrm{k})}, v_{i_{k}, \mathrm{t}}^{(\mathrm{k})}\right\}_{k \in\{h, f\}, i_{k} \in[0,1], t=0}^{t=\infty} ;$ (vii) time paths of wages and pricing kernels $\left\{\omega_{t}^{(k)}, M_{t, t+1}^{(k)}, M_{t, t+1}^{(k), l o c}\right\}_{k \in\{h, f\}, t=0}^{t=\infty}$; and (viii) time paths of the Pareto share $\left\{S_{t}\right\}_{t=0}^{t=\infty}$, such that (a) the representative household maximizes lifetime utility by optimally choosing the allocation of final goods via trading in Arrow-Debreu securities (equations (1), (A9), (A10), and (A11)); (b) the final good firm maximizes the present value of future dividends by choosing labor, capital investment and the demand for intermediate goods (equations (7), (A12), (A13), and (A14)) subject to the capital accumulation equation (8); (c) incumbents and potential entrants maximize present values of their future net profits by choosing the monopoly price and R\&D expenditures (equations (9), (14), (15), (A16), (A21), (A22), (A23), and (A24)); (d) the labor market clears (i.e., $L_{t}^{(k)} \equiv 1$ for $\left.k=h, f\right)$; and (e) the final good market clears (equations (2), and (16)), given the vector of exogenous state variables $\left\{z_{t}, a_{t}^{(k)}, \omega_{\mathrm{E}, \mathrm{k}, \mathrm{t}}\right\}_{k=h, f}$, whose processes are stated in equations (4), (5), (11).

\section{A.5 Asset Prices}

Using the stochastic discount factors, every payoff stream can be priced. Additionally to the incumbent's value, I will price the final good firm's dividend stream using the following Bellman equation

$$
V_{d, t}^{(k)}=D_{t}^{(k)}+\mathbb{E}_{t}\left[\mathbb{M}_{t, t+1}^{(k), l o c} V_{d, t+1}^{(k)}\right]
$$

Aggregate dividends in each country are defined by the sum of the profits of the final good and intermediate good sector. Therefore, the aggregate stock market value in country $k$ is given by

$$
D_{a, t}^{(k)}=D_{t}^{(k)}+\Pi_{t}^{(k)}-S_{I, k, t}^{(k)}-P_{t}^{(k)} S_{I,-k, t}^{(k)}, \quad V_{a, t}^{(k)}=D_{a, t}^{(k)}+\mathbb{E}_{t}\left[\mathbb{M}_{t, t+1}^{(k), l o c} V_{a, t+1}^{(k)}\right]
$$

Log returns of the final good firm and the aggregate stock market are defined by

$$
r_{d, t+1}^{(k)}=\log \left(\frac{V_{d, t+1}^{(k)}}{V_{d, t}^{(k)}-D_{t}^{(k)}}\right), \quad r_{a, t+1}^{(k)}=\log \left(\frac{V_{a, t+1}^{(k)}}{V_{a, t}^{(k)}-D_{a, t}^{(k)}}\right) .
$$

The incumbent's log return is defined as

$$
r_{I, t+1}^{(k)}=\log \left(\frac{\left(\kappa_{\mathrm{I}, \mathrm{k}} \Phi_{\mathrm{I}}^{(\mathrm{k})}\left(s_{\mathrm{I}, \mathrm{t}}^{(\mathrm{k})}\right)+\kappa_{\mathrm{D}, \mathrm{k}}\left(1-\Phi_{\mathrm{I}}^{(\mathrm{k})}\left(s_{\mathrm{I}, \mathrm{t}}^{(\mathrm{k})}\right)-s_{\mathrm{E}, \mathrm{t}}^{(\mathrm{k})} \Phi_{\mathrm{E}, \mathrm{t}}^{(\mathrm{k})}\left(s_{\mathrm{E}, \mathrm{t}}^{(\mathrm{k})}\right)\right)\right) v_{t+1}^{(k)}}{v_{t}^{(k)}-\left(\pi_{t}^{(k)}-s_{\mathrm{I}, \mathrm{k}, \mathrm{t}}^{(\mathrm{k})}-P_{t}^{(k)} s_{\mathrm{I},-\mathrm{k}, \mathrm{t}}^{(\mathrm{k})}\right)}\right) .
$$

Finally, the risk-free rate in country $k$ is determined by

$$
1=\mathbb{E}_{t}\left[\mathbb{M}_{t, t+1}^{(k), l o c} R_{f, t}^{(k)}\right]
$$

\section{B Deterministic Steady State and Calibration}

To obtain the deterministic steady state of the economy, I have to assume that there is no shock in the economy, i.e., $\varepsilon_{a, t}^{(k)} \equiv \varepsilon_{z, t} \equiv \varepsilon_{t+1}^{\omega_{\mathrm{E}, \mathrm{k}}} \equiv 0$ for all $t \geq 0$ and for $k=h, f$, and that every quantity $X$ is in the steady state, i.e., $X_{t+1}=X_{t}$ for all $t \geq 0$.

Furthermore, I append the resulting equation system by two additional conditions per country. Using empirial evidence for U.S. data over the period from January 1975 to June 2013 in Bena, Garlappi, and 
Grüning (2014), the average ratio of patents originated by entrants in a given quarter (measured as firms that did not patent prior to the beginning of this quarter) is $10.67 \%$ and this entry measure fluctuates between roughly 5\% and 15\% in the period 1985-2008 (see Bena, Garlappi, and Grüning (2014), Figure $1)$. The time trend shows a declining importance of entrants despite a growing number of entrants. Finally, the annual growth rate of GDP in U.S. data from 1929-2008 is $1.89 \%$ (or $0.4725 \%$ quarterly) as documented by Benzoni, Collin-Dufresne, and Goldstein (2011).

This entry measure will be called rate of radical innovation as in Bena, Garlappi, and Grüning (2014) and is defined by the following expression in the model (see also equation (18))

$$
\Gamma_{t}^{(k)}=\frac{\eta_{\mathrm{E}, \mathrm{k}}\left(s_{\mathrm{E}, \mathrm{t}}^{(\mathrm{k})}\right)^{\omega_{\mathrm{E}, \mathrm{k}, \mathrm{t}}}}{\eta_{\mathrm{I}, \mathrm{k}}\left(s_{\mathrm{I}, \mathrm{t}}^{(\mathrm{k})}\right)^{\omega_{\mathrm{I}, \mathrm{k}}}+\eta_{\mathrm{E}, \mathrm{k}}\left(s_{\mathrm{E}, \mathrm{t}}^{(\mathrm{k})}\right)^{\omega_{\mathrm{E}, \mathrm{k}, \mathrm{t}}}} .
$$

Thus, I calibrate my model to match the empirical growth rate and the mean of the rate of radical innovation by adjusting the parameters $\omega_{\mathrm{I}, \mathrm{k}}$ and $\overline{\omega_{\mathrm{E}, \mathrm{k}}}$ in both countries. Thus, I add the following four equations (two per country) to the deterministic steady state equation system $(k=h, f)$ :

$$
\begin{aligned}
1+0.004725 & =\kappa_{\mathrm{D}, \mathrm{k}}+\left(\kappa_{\mathrm{I}, \mathrm{k}}-\kappa_{\mathrm{D}, \mathrm{k}}\right) \eta_{\mathrm{I}, \mathrm{k}}\left(\widehat{S}_{I, s s}^{(k)}\right)^{\omega_{\mathrm{I}, \mathrm{k}}}+\left(\kappa_{\mathrm{E}, \mathrm{k}}-\kappa_{\mathrm{D}, \mathrm{k}}\right) \eta_{\mathrm{E}, \mathrm{k}}\left(\widehat{S}_{E, s s}^{(k)}\right)^{\bar{\omega}_{\mathrm{E}, \mathrm{k}}} \\
0.1067 & =\Gamma_{s s}^{(k)}=\frac{\eta_{\mathrm{E}, \mathrm{k}}\left(\widehat{S}_{E, s s}^{(k)}\right)^{\omega_{\mathrm{E}, \mathrm{k}}}}{\eta_{\mathrm{I}, \mathrm{k}}\left(\widehat{S}_{I, s s}^{(k)}\right)^{\omega_{\mathrm{I}, \mathrm{k}}}+\eta_{\mathrm{E}, \mathrm{k}}\left(\widehat{S}_{E, s s}^{(k)}\right)^{\overline{\omega_{\mathrm{E}, \mathrm{k}}}}} .
\end{aligned}
$$

\section{Data}

This appendix describes the sources for the values in the "Data" columns of the tables. Most values have been compiled from previous studies. The data sources for my own empirical analysis are also explained in detail below.

\section{Within-Country Macroeconomic Dynamics (Table 2)}

- The moments for realized annual consumption growth are taken from Benzoni, Collin-Dufresne, and Goldstein (2011) for US data between 1929 and 2008.

- The within-country correlations of quarterly growth rates are taken from Rabanal, Rubio-Ramírez, and Tuesta (2011) for US data between 1973 and 2006.

- The quarterly moments for the rate of radical innovations and innovation probabilities of incumbents and entrants are taken from Bena, Garlappi, and Grüning (2014) for US data between 1985 and 2008 .

\section{Asset Pricing Moments (Table 3)}

- The annual moments for the risk-free rate and excess market returns are taken from Benzoni, Collin-Dufresne, and Goldstein (2011) for US data between 1929 and 2008.

\section{International Moments (Table 4)}

- The values for quarterly exchange rate volatility and quarterly cross-country correlations are taken from Rabanal, Rubio-Ramírez, and Tuesta (2011) for quarterly data between 1973 and 2006 (US vs. a "Rest of the World" aggregate which includes the Euro area, the United Kingdom, Canada, Japan, and Australia). 
- The correlation between aggregate $R \& D$ expenditure growth is computed using annual data from the Global Financial Database between 1981 and 2006 and represents the mean of all correlation pairs across the G-7 countries (US, UK, Germany, France, Italy, Japan, Canada). The time series for all sectors RED expenditure is used for all countries except Canada. Due to the unavailability of this series for Canada, I use data from the OECD (total R\&D expenditures of business enterprises BERD) in this case.

- The correlation between the net exports to GDP ratio and GDP is taken from Raffo (2008) for quarterly data between 1980 and 2004 and represents the correlation for the pair US vs. EU-15 countries (i.e. the correlation of US net exports to the EU-15 countries as a ratio of US GDP to US GDP).

- The correlation between excess market returns is computed using monthly data from Datastream and the Global Financial Database between 1973 and 2006 and represents the mean of all correlation pairs across the G-7 countries (US, UK, Germany, France, Italy, Japan, Canada). The returns are downloaded from Datastream and represent the respective country's MSCI Total Return index. The monthly risk-free rate series is from the Global Financial Database. I use 3-month treasury bill yields quoted in percent by annum divided by 12 .

- The correlation between the risk-free rates is computed using quarterly data from the Global Financial Database between 1973 and 2006 and represents the mean of all correlation pairs across the G-7 countries (US, UK, Germany, France, Italy, Japan, Canada). To proxy for the risk-free rates in these countries I use 3-month treasury bill yields quoted in percent per annum.

\section{Sensitivity Analysis}

In this appendix, I will provide some more results regarding the novel way I use to model technology spillover. Hence, this appendix provides a sensitivity analysis with respect to the home bias parameters for R\&D expenditures. Based on the calibration in the column with heading "Technology spillover" in Table 1, I vary the home bias parameters $\phi_{\mathrm{I}, \mathrm{k}}$ and $\phi_{\mathrm{E}, \mathrm{k}}$ to analyze the equilbrium implications of different degrees of technology spillover. The model with the benchmark value of 0.90 is contrasted to the models employing four other values, i.e. $\phi_{\mathrm{I}, \mathrm{k}}=\phi_{\mathrm{E}, \mathrm{k}} \in\{0.85,0.875,0.925,0.95\}$. For each of these values I also change the productivity shock volatilities $\sigma_{z}$ and $\sigma_{a, k}$ and the R\&D elasticity parameters $\overline{\omega_{\mathrm{E}, \mathrm{k}}}$ and $\omega_{\mathrm{I}, \mathrm{k}}$ to keep fixed the mean and volatility of consumption growth, the cross-country correlation of output growth, and the mean rate of radical innovation across the four model parameterizations. Excactly as I did before when analyzing the different models in Section 4. The results are summarized in Table 5.

The higher these home bias parameters, the lower is the amount of goods traded between the countries. Hence, the pressure for households to achieve their desired risk-sharing scheme via financial markets increase. This leads to an increasing exchange rate growth volatility for higher $\phi_{\mathrm{I}, \mathrm{k}}$ and $\phi_{\mathrm{E}, \mathrm{k}}$. The exchange rate growth volatility observed in the data could thus be matched by the model with home bias parameters equal to some value between 0.925 and 0.95 .

By inspecting Table 5 one realizes that $\mathrm{R} \& \mathrm{D}$ expenditure growth rates are increasingly correlated across countries for increasing home bias parameters. Consequently, long-run risks induced by R\&D expenditures are more highly internationally correlated, which can also be noticed by the increasing cross-country correlation of expected consumption growth rates. Compared to the parameterizations with lower home bias parameters, imports and exports of final goods for R\&D investments are less important and thus the household reacts to shocks that induce a higher incentive to invest in R\&D by rather substituting consumption for R\&D expenditures than importing or exporting a higher or lower amount of goods. In contrast to the economy without technology spillover however the household still has the possibility to import and export and adjust the quantities. When a foreign productivity shock materializes, the incentives to invest in $R \& D$ increase due to the positive effect on the home country's pricing kernel. The household thus substitutes the home and foreign good's contribution to consumption for an increase in 
the home and foreign good's contribution of both incumbents' and entrants' R\&D expenditures. Hence, consumption decreases and $\mathrm{R} \& \mathrm{D}$ expenditures increase. The higher the home bias parameters are set, the larger is the described effect. The larger decrease in consumption in response to foreign productivity shocks leads to a stronger negative spillover in consumption dynamics. This results into the cross-country correlation of consumption decreasing with increasing home bias parameters. The opposite happens for $\mathrm{R} \& \mathrm{D}$ expenditures as a larger increase in $\mathrm{R} \& \mathrm{D}$ expenditures in response to foreign productivity shocks induces a higher degree of positive technology spillover. This explains the increasing cross-country correlations of $\mathrm{R} \& \mathrm{D}$ expenditure growth rates. However, when home bias parameters are set to 1 (as in Section 4.2), there is no possibility to adjust the international good trade quantities and thus the only effect comes from a comovement in the pricing kernels which leads to the observed low degree of technology spillover. Hence, this constitutes an interesting non-linearity of technology spillover dynamics with respect to the degree of home bias in $R \& D$ investments. First, the correlations of $R \& D$ expenditures across countries increase with the degree of home bias. For home bias parameters too high this trend has to reverse as the analysis of the limiting case, where home bias parameters are set to 1 , has shown.

The increased correlation of incumbents' $R \& D$ expenditures and of expected consumption growth rates explains the behavior of the cross-country correlations of returns for varying degrees of home bias. First, the final good firm return and risk-free rate correlations mimic the behavior of expected consumption growth correlation across the columns. There are no additional effects from the final good firm's dividends as those are essentially given by output and the output growth correlation is held constant across the parameterizations. Second, incumbents returns are increasingly negatively correlated due to the increased correlation of $R \& D$ expenditures which represent an outflow to incumbent firms' dividends. Last, the aggregate market return correlations display a mild decrease when the home bias parameters are decreased from 0.90 to 0.85 and a very steep decrease when the home bias parameters are increased from 0.90 to 0.95 . The steep decrease is due to the increasing cross-country correlation of incumbent R\&D expenditures again. Due to this effect incumbent returns should become more highly correlated also for home bias parameters below 0.90 . The reason why this is not the case is that in this region the lower correlation of expected consumption growth rates dominates the effect coming from incumbent $R \& D$ expenditures and thus the incumbent firm return correlation is also mildly decreasing for home bias parameters below 0.90 .

The negative correlation of net exports with output becomes less pronounced when home bias parameters are increased. As described above increasing the home bias parameters lead to a higher reaction for imports from the foreign country in percentage terms when a foreign productivity shock materializes, which in turn strengthens the spillover effects in consumption and R\&D expenditures. This means that more is exported when domestic productivity shocks occur and thus the correlation of net exports with output increases with the degree of home bias. The last moments to be discussed are the R\&D expenditure shares. The fraction of output that is devoted to R\&D expenditures is increasing in home bias parameters. This is due to less efficient $R \& D$ technologies if home bias parameters are higher, i.e. $\overline{\omega_{\mathrm{E}, \mathrm{k}}}$ and $\omega_{\mathrm{I}, \mathrm{k}}$ have to increase to keep the growth rate in the economy fixed. ${ }^{24}$ Less efficient $R \& D$ technologies however require that a higher fraction of output is invested in $R \& D$. The composition of aggregate $R \& D$ expenditures between incumbents and entrants does not change significantly across the economies as the mean of the rate of radical innovation is also kept fixed across the columns.

\footnotetext{
${ }^{24}$ Ceteribus paribus, this means that economies with higher home bias parameters are more efficient. This is due the fact that a higher home bias parameter implies a more linear technology (a Cobb-Douglas aggregate with a home bias parameter of 0.5 would be the most non-linear as both components have exponents far from 1). Hence, $R \& D$ technologies have to get less efficient when one ones to keep the growth rate the sam as with lower home bias parameters.
} 


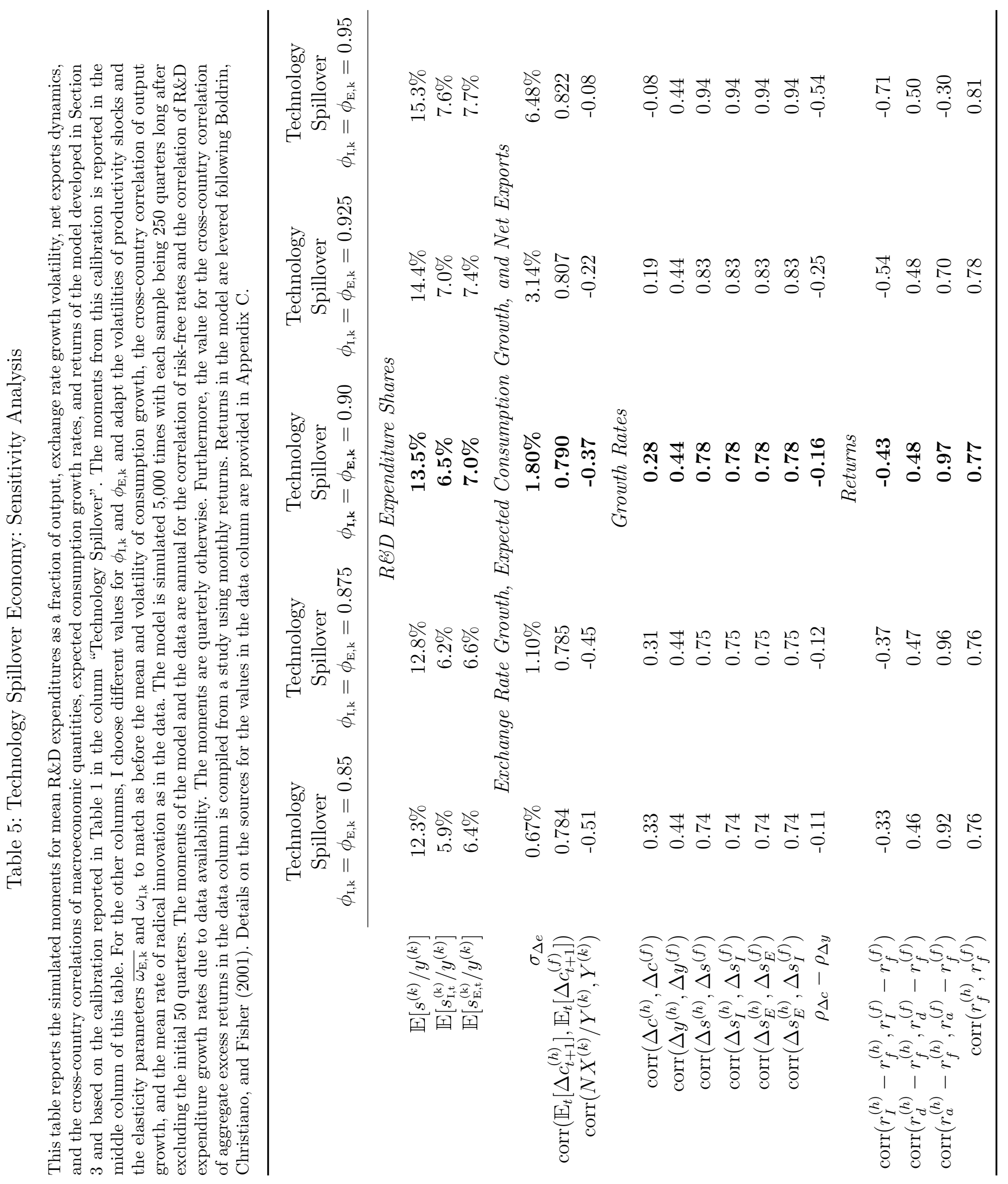




\section{References}

Acemoglu, D. (2010): Introduction to Modern Economic Growth. Princeton University Press.

Acemoglu, D., And D. V. CaO (2010): "Innovation by Entrants and Incumbents," Working Paper.

Aghion, P., C. Harris, P. Howitt, and J. Vickers (2001): "Competition, Imitation and Growth with Step-by-Step Innovation," Review of Economic Studies, 68, 467-492.

Aghion, P., And P. Howitt (1992): "A Model of Growth Through Creative Destruction," Econometrica, 60(2), 323-351.

- (1998): Endogenous Growth Theory. MIT Press. (2009): The Economics of Growth. MIT Press.

Ai, H., M. M. Croce, and K. Li (2013): "Toward a quantitative general equilibrium asset pricing model with intangible capital," Review of Financial Studies, 26(2), 491530 .

AI, H., AND D. KIKU (2013): "Growth to value: Option exercise and the cross section of equity returns," Journal of Financial Economics, 107(2), 325-349.

AkCigit, U., AND W. R. KerR (2010): "Growth through heterogeneous innovations," Discussion paper, National Bureau of Economic Research.

Alessandria, G., And H. Choi (2007): "International Trade and Macroeconomic Dynamics with Heterogeneous Firms," The Quarterly Journal of Economics, 122(1), 289 336.

Backus, D., P. J. Kehoe, and F. E. Kydland (1994): "Dynamics of the trade balance and the terms of trade: The j-curve?," American Economic Review, 84(1), 84-103.

Backus, D., And G. Smith (1993): "Consumpton and real exchange rates in dynamic exchange economie with nontraded goods," Journal of International Economics, 35, $297-316$.

Bansal, R., D. Kiku, and A. Yaron (2010): "Long run risks, the macroeconomy, and asset prices," American Economic Review, 100(2), 542-546.

- (2012): "An Empirical Evaluation of the Long-Run Risks Model for Asset Prices," Critical Finance Review, 1(1), 183-221.

Bansal, R., And A. YAron (2004): "Risks for the long run: A potential resolution of asset pricing puzzles," Journal of Finance, 59, 1481-1509. 
Bartelsman, E., J. Haltiwanger, and S. Scarpetta (2004): "Microeconomic evidence of creative destruction in industrial and developing countries," IZA Discussion Papers No. 1374.

Beeler, J., And J. Y. Campbell (2012): "The Long-Run Risks Model and Aggregate Asset Prices: An Empirical Assessment," Critical Finance Review, 1(1), 141-182.

Bena, J., L. Garlappi, and P. Grüning (2014): "Heterogeneous Innovations, Firm Creation and Destruction, and Asset Prices," Working Paper.

Benzoni, L., P. Collin-Dufresne, and R. S. Goldstein (2011): "Explaining asset pricing puzzles asssociated with the 1987 market crash," Journal of Financial Economics, 101, 552-573.

Bernard, A. B., J. Eaton, J. B. Jensen, and S. Kortum (2003): "Plants and Productivity in International Trade," American Economic Review, 93(4), 1268-1290.

Boldrin, M., L. J. Christiano, and J. D. Fisher (2001): "Habit Persistence, Asset Returns and the Business Cycle," American Economic Review, 91(1), 149-166.

Broda, C., And D. E. Weinstein (2010): "Product Creation and Destruction: Evidence and Price Implications," American Economic Review, 100(3), 691-723.

Coe, D. T., E. Helpman, and A. W. Hoffmaister (1997): "North-South R\&D spillovers," The Economic Journal, 107, 134-149.

Colacito, R., And M. M. Croce (2011): "Risks for the Long Run and the Real Exchange Rate," Journal of Political Economy, 119(1), 153-181.

(2013): "International Asset Pricing with Recursive Preferences," Journal of Finance, 68(6), 2651-2686.

Colacito, R., M. M. Croce, S. Ho, and P. Howard (2014): "BKK the EZ Way: International Long-Run Growth News and Capital Flows," Working Paper.

Comin, D. A., M. Gertler, and A. M. Santacreu (2009): "Technology innovation and diffusion as sources of output and asset price fluctuations," Discussion paper, National Bureau of Economic Research.

Croce, M. M. (2014): "Long-Run Productivity Risk: A New Hope for Production-Based Asset Pricing?," Journal of Monetary Economics, Forthcoming.

Eaton, J., And S. Kortum (1999): "International Technology Diffusion: Theory and Measurement," International Economic Review, 40(3), 537-570.

Eaton, J., S. Kortum, and F. Kramarz (2004): "Dissecting Trade: Firms, Industries, and Export Destinations," American Economic Review, 94(2), 150-154. 
Epstein, L. G., And S. Zin (1989): "Substitution, Risk Aversion, and the Temporal Behavior of Consumption Growth and Asset Returns I: A Theoretical Framework," Econometrica, 57(4), 937-969.

Erceg, C., L. Guerrieri, and C. Gust (2008): "Trade Adjustment and the Composition of Trade," Journal of Economic Dynamics and Control, 32(8), 2622-2650.

FAmA, E. (1984): "Forward and spot exchange rates," Journal of Monetary Economics, $14,319-338$.

FitzGerald, D. (2012): "Trade Costs, Asset Market Frictions, and Risk Sharing," American Economic Review, 102(6), 2700-2733.

Gavazzoni, F., And A. M. Santacreu (2014): "International Comovement through Endogenous Long Run Risk," Working Paper.

Ghironi, F., And M. J. Melitz (2005): "International Trade and Macroeconomic Dynamics with Heterogeneous Firms," The Quarterly Journal of Economics, 120(3), 865915.

Grossman, G. M., And E. Helpman (1991): "Quality Ladders in the Theory of Growth," Review of Economic Studies, 58(1), 43-61.

Jermann, U. J. (1998): "Asset Pricing in production economies," Journal of Monetary Economics, 41, 257-275.

JinnaI, R. (2014): "Innovation, product cycle, and asset prices," Review of Economic Dynamics, Forthcoming.

Klette, T. J., And S. Kortum (2004): "Innovating Firms and Aggregate Innovation," Journal of Political Economy, 112(5), 986-1018.

Kung, H., And L. Schmid (2013): "Innovation, Growth, and Asset Prices," Journal of Finance, Forthcoming.

Lewis, K. K. (2011): "Global Asset Pricing," Annual Review of Financial Economics, $3,435-466$.

LiaO, W., and A. M. Santacreu (2013): "The Trade Comovement Puzzle and the Margins of International Trade," Working Paper.

Loualiche, E. (2014): "Asset Pricing with Entry and Imperfect Competition," Working Paper.

Rabanal, P., J. F. Rubio-Ramírez, and V. Tuesta (2011): "Cointegrated TFP processes and international business cycles," Journal of Monetary Economics, 58, 156171. 
RAFFO, A. (2008): "Net exports, consumption volatility and international business cycle models," Journal of International Economics, 75, 14-29.

Romer, P. M. (1990): "Endogenous Technological Change," Journal of Political Economy, 98(5), 71-102.

Santacreu, A. M. (2014): "Innovation, Diffusion, and Trade: Theory and Measurement," Working Paper.

Schumpeter, J. A. (1934): The Theory of Economic Development. Harvard University Press.

— (1942): "Creative destruction," Capitalism, socialism and democracy.

Tretvoll, H. (2013): "Real exchange rate variability in a two-country business cycle model," Working Paper.

WeIL, P. (1990): "Nonexpected Utility in Macroeconomics," The Quarterly Journal of Economics, 105(1), 29-42. 


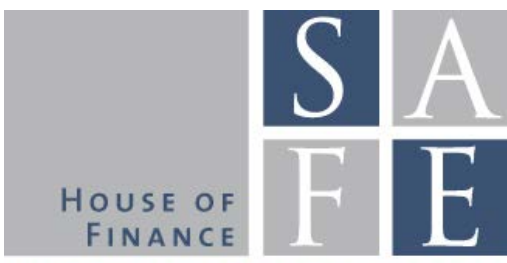

WORKING PAPER SERIES

\section{Recent Issues}

No. 82 Edgar Vogel, Alexander Ludwig, Axel Börsch-Supan

No. 81 Jens-Hinrich Binder

No. 80 Enrique G. Mendoza, Linda L. Tesar, Jing Zhang

No. 79 Òscar Jordà, Alan M. Taylor

No. 78 Harris Dellas, Dirk Niepelt

No. 77 Benjamin Born, Gernot J. Müller, Johannes Pfeifer

No. 76 Alberto Alesina, Carlo Favero, Francesco Giavazzi

No. 75

Markus Behn, Rainer Haselmann, Vikrant Vig

No. 74 Nicole Branger, Patrick Konermann, Christoph Meinerding, Christian Schlag

No. 73 Max Groneck, Alexander Ludwig, Alexander Zimpel

No.72 Alexander Ludwig, Matthias Schön

No. 71 Daniel Harenberg, Alexander Ludwig

No. 70 Deyan Radev
Aging and Pension Reform: Extending the Retirement Age and Human Capital Formation

Resolution Planning and Structural Bank Reform within the Banking Union

Saving Europe?: The Unpleasant Arithmetic of Fiscal Austerity in Integrated Economies

The Time for Austerity: Estimating the Average Treatment Effect of Fiscal Policy

Austerity

Does Austerity Pay Off?

The Output Effect of Fiscal Consolidation Plans

The Limits of Model-Based Regulation

Equilibrium Asset Pricing in Networks with Mutually Exciting Jumps

A Life-Cycle Model with Ambiguous Survival Beliefs

Endogenous Grids in Higher Dimensions: Delaunay Interpolation and Hybrid Methods

Social Security in an Analytically Tractable Overlapping Generations Model with Aggregate and Idiosyncratic Risk

Assessing Systemic Fragility - a Probabilistic Perspective 